\title{
La movilidad de los judíos a ambos lados de la frontera entre las Coronas de Castilla y Aragón durante el siglo XIV
}

\author{
Máximo Diago Hernando * \\ Instituto de Historia - CSIC, Madrid
}

Los judíos que residieron en la Península Ibérica durante los siglos bajomedievales se caracterizaron por ser personas muy proclives a la movilidad geográfica. Esta tendencia se desarrolló con especial intensidad entre los que tuvieron como principal dedicación las actividades mercantiles y financieras, aunque no hay que descartar que se diese en igual grado entre los dedicados a otro tipo de actividades, como, por ejemplo, el trabajo artesanal, puesto que las fuentes documentales conservadas aportan bastante menos información sobre estos últimos que sobre los primeros. Y, a pesar de ello, también se pueden encontrar en ellas noticias sobre individuos que responden a este perfil que manifestaron una fuerte predisposición a cambiar de residencia en busca de nuevas oportunidades para el desempeño de su trabajo. Como ejemplo paradigmático sirve recordar el caso de Nemies Iseo e Isach Iseo, dos judíos cardadores de lana oriundos del reino de Castilla que en 1404 residían en la ciudad valenciana de Castellón de la Plana, y solicitaron entonces al rey

*mdiago@ceh.csic.es.

Sefarad 63 (2003) págs. 237-282

(1) CSIC

ISSN 037-0894 
Martín el Humano que les autorizase a mudar su domicilio a otro lugar, porque allí no podían ganarse la vida mediante el desempeño de su oficio ${ }^{1}$.

La constatación de esta proclividad a la movilidad geográfica, aunque concuerda con el tópico del « judío errante» que vaga por el mundo por no formar parte de ninguna «nación», resulta, sin embargo, sorprendente si tenemos en cuenta que la legislación vigente en esta época en los reinos hispanos imponía severas limitaciones a la libertad de movimientos a los hebreos en ellos residentes. En concreto, en la Corona de Aragón, según nos recuerda Fritz Baer, los judíos que deseasen abandonar temporalmente el reino, para resolver determinados negocios fuera de él, sólo podían hacerlo con la condición de dejar como rehenes a sus mujeres e hijos, y de depositar ciertos bienes como garantía de que continuarían pagando sus impuestos $^{2}$. E incluso dentro del propio territorio de la Corona, los miembros de las comunidades judía y musulmana de las ciudades y villas del realengo tenían prohibido mudar su domicilio a otro lugar, si no habían obtenido previamente licencia del rey o del baile general para hacerlo.

Esta medida tenía como objetivo evitar su traslado en masa a lugares de señorío, para garantizar el mantenimiento de la capacidad contributiva de las aljamas realengas. Y así nos lo confirma, por ejemplo, la decisión tomada en 1388 por el monarca aragonés que, enterado de que muchos judíos y moros que vivían en sus ciudades de Calatayud, Daroca, Teruel, Tarazona y Montalbán se habían ausentado de ellas sin su licencia o la del baile general de Aragón, y habían pasado a fijar su domicilio en lugares de señorío, ordenó que todos los que hubiesen procedido así fuesen inmediatamente devuel-

1 ACA [= Archivo de la Corona de Aragón], C [= Cancillería], reg. 2175-80 (indicamos siempre el número de registro $\mathrm{y}$, seguido de guión, el primer folio del documento), Valencia 14-IV-1404.

${ }^{2}$ Fritz BAER, Studien zur Geschichte der Juden im Königreich Aragonien während des 13. und 14. Jahrhunderts (Berlin 1913) pág. 14. 
tos a sus lugares de origen. Pero, al mismo tiempo, dejó abierta la posibilidad de que permaneciesen en sus nuevos lugares de residencia siempre que se comprometiesen a contribuir con alguna de las aljamas de los lugares de realengo próximos, situados a una distancia inferior a cuatro leguas ${ }^{3}$. De este modo reconoció de forma abierta que su interés en restringir la libertad de movimientos de los judíos tenía una motivación de naturaleza estrictamente fiscal, lo que resulta fácilmente comprensible teniendo en cuenta la elevada capacidad contributiva de aquéllos, muy superior a la de los mudéjares.

En otras ocasiones nos consta, no obstante, que los monarcas aragoneses tomaron drásticas medidas para poner freno a las huidas de judíos de las aljamas de sus ciudades. Y, como testimonio ilustrativo, sirva recordar lo dispuesto por Martín I en 1406, como reacción al abandono de sus domicilios sin licencia regia por varios judíos de Calatayud, que habían pasado a residir en diversos lugares de señorío. En efecto, considerando éste el grave perjuicio que estos cambios de domicilio no autorizados causaban a las regalías y a la propia aljama de Calatayud, dio orden de que todos los judíos que se hubiesen marchado sin su licencia tornasen a residir a esta ciudad en un plazo de dos meses, so pena de que, si pasado dicho plazo no habían obedecido, fuesen apresados como «albarranes» por sus oficiales, donde quiera que se encontrasen, y entregados al tesorero del rey. Pero, quizás porque dudaba de la eficacia de esta amenaza, dispuso además añadir otra de carácter espiritual. Así, ordenó a los clavarios y a los jueces de la aljama bilbilitana (dayani) que, si pasado el plazo de los dos meses no tornaban a sus domicilios los judíos desplazados, «los metan en scomunicación del niduy», según en ley de judíos era acostumbrado, haciendo que se les pregonase por excomulgados en las sinagogas de la judería de la aljama una vez cada semana, el día del sábado antes de salir de oración, hasta que tornasen a sus domicilios ${ }^{4}$.

ACA, C, reg. 1946-97v, Zaragoza, 8-VII-1388.

${ }^{4}$ ACA, C, reg. 2212-148v, Valencia, 18-VIII-1406. 
A pesar de todas estas duras medidas orientadas a limitar la movilidad geográfica de los judíos, lo cierto, sin embargo, es que éstos cambiaron de domicilio con relativa facilidad, y no sólo en el interior de los distintos reinos, sino que también fueron muchos los que en el transcurso de sus vidas abandonaron su reino de origen para fijar su residencia en otro. Y así vamos a tratar de ponerlo de manifiesto en el presente artículo, centrándonos en el análisis de la movilidad geográfica de los judíos entre los territorios de las Coronas de Castilla y Aragón durante el siglo XIV. Entendemos, en efecto, que se trata de una faceta no suficientemente valorada de las condiciones de vida de los judíos hispanos durante la Baja Edad Media, y que su análisis presenta un notable interés, no sólo desde la perspectiva de la historia de los judíos, sino también desde la de la valoración de las consecuencias prácticas que tuvo en esta época la división en reinos del espacio peninsular.

\section{MOVILIDAD GEOGRÁFICA DE LOS JUDÍOS EN LOS ÁMBITOS FRON- TERIZOS}

A los dos lados de la línea fronteriza que separaba la Corona de Aragón de la de Castilla proliferaron las aljamas judías, algunas de las cuales llegaron a ser muy populosas, como es el caso, por ejemplo, de las de Soria y Calatayud. Con frecuencia se trató también de aljamas en las que se desarrolló una intensa actividad económica, en los terrenos artesanal, mercantil y financiero. Y llama la atención comprobar cómo para muchos de los judíos que residieron en ellas la existencia de la frontera no representó una realidad que marcase de forma significativa sus vidas, ni en el terreno profesional ni en otros muchos.

Una buena prueba nos la proporciona la constatación de la frecuencia con que judíos residentes en estas ciudades fronterizas trasladaron sus domicilios a otras ciudades próximas, pero localizadas al otro lado de la frontera, sin por ello desvincularse plenamente de su 
lugar de origen, donde solieron continuar manteniendo fuertes intereses económicos. Así lo atestigua, por ejemplo, el caso de Iuce Azarías, judío castellano que, habiendo estado domiciliado durante mucho tiempo en la villa soriana de Deza, muy próxima a la frontera con Aragón, donde contrajo matrimonio, pasó después a residir en la ciudad aragonesa de Calatayud, sin por ello dejar de ser propietario de diversos bienes en Deza. Resulta muy sintomático comprobar que en su nuevo lugar de residencia, Calatayud, los encargados por la aljama de calcular su capacidad contributiva, los llamados «taxatores sive distribuitores peytarum», tuvieron en cuenta el valor de estos bienes que había dejado tras de sí en Castilla para fijar la tasa por la que debía contribuir en los repartos de impuestos realizados por aquélla. Y por ello este judío, al serle embargados por las autoridades castellanas sus bienes en Deza tras el estallido de la guerra entre Castilla y Aragón en 1356, denunció que los repartidores de impuestos de la aljama bilbilitana le estaban sometiendo a una insoportable opresión, por haber mantenido inalterada su cuota contributiva, a pesar de que había perdido una parte muy importante de su hacienda, la que le había sido embargada en Castilla ${ }^{5}$.

En otras ocasiones, por el contrario, algunos judíos trataron de aprovechar sus traslados de domicilio al otro lado de la frontera para eludir el pago de deudas contraídas en sus reinos de origen. Así nos lo pone de manifiesto, por ejemplo, la denuncia presentada en 1372 por Salamon German, judío de Calatayud, contra Jacob Façan, judío que había trasladado recientemente su domicilio de Ariza, en el reino de Aragón, a Medinaceli, en el reino de Castilla, y le estaba adeudando cincuenta libras jaquesas, por virtud de un contrato de obligación otorgado en Aragón, las cuales ahora se negaba a pagarle ${ }^{6}$.

\footnotetext{
5 ACA, C, reg. 1179-4v, Calatayud, 10-V-1361. Comisión del rey Pedro IV al baile de Calatayud para que haga justicia a Iuce Azarías. Se hace constar que lo que el judío había dejado en Deza era lo siguiente: "plura debita et quasi omnia bona sua».

${ }^{6}$ ACA, C, reg. 762-47, Zaragoza, 14-II-1372.
} 
En estos casos, en efecto, resultaba bastante más difícil forzar a los deudores a cumplir con los compromisos contraídos con sus acreedores, por haber pasado a residir unos y otros en dos reinos diferentes. Por ello, los acreedores se solían ver forzados a recurrir a otros procedimientos para alcanzar justicia, como era por ejemplo solicitar el embargo de los bienes que el deudor pudiese poseer en el reino donde estaba domiciliado el acreedor. En concreto es lo que hizo el ya mencionado Salamon German, quien obtuvo provisión del rey Pedro IV ordenando a sus oficiales que ejecutasen en cualesquier bienes que pudiesen encontrar en el reino de Aragón pertenecientes a Jacob Façan, residente entonces en Medinaceli, hasta que Salamon German hubiese recibido enmienda suficiente por la cantidad que se le adeudaba, y por los gastos en que hubiese incurrido para reclamar su pago.

No obstante, cuando esta opción no era practicable, por no haber bienes susceptibles de embargo, era forzado recurrir a otras alternativas, y la más frecuente fue la reclamación de una carta de marca contra los «conciudadanos» del deudor reacio a honrar sus compromisos, a los que se hacía corresponsables del pago de una deuda contraída por una persona con la que sólo tenían en común el hecho de ser súbditos de un mismo monarca ${ }^{7}$.

Pero, dejando a un lado esta cuestión, sobre la que volveremos más adelante para analizar en detalle las consecuencias en el terreno económico de la movilidad de los judíos en torno a la frontera castellano-aragonesa, nos interesa ahora llamar la atención sobre el hecho de que la facilidad con que los judíos cambiaron de domicilio de unos lugares a otros a ambos lados de esta frontera propició que a veces se planteasen incluso dudas sobre la auténtica «nacionali-

\footnotetext{
${ }^{7}$ Más detalles sobre la utilización de las cartas de marca como procedimiento de compensación, desde la perspectiva de las relaciones entre las Coronas de Castilla y Aragón durante el siglo XIV, en M. Diago Hernando, «La 'quema'. Trayectoria histórica de un impuesto sobre los flujos comerciales entre las coronas de Castilla y Aragón durante los siglos XIV y XV», Anuario de Estudios Medievales 30/1 (2000) págs. 91-156.
} 
dad» de algunos de ellos. Así ocurrió, por ejemplo, en 1328 con Mosse Passago, judío de Calatayud, a quien, según su propio testimonio, le robaron 200 mrs. castellanos en un lugar de la Orden de Calatrava llamado Quadrón, cuando regresaba de las ferias de Alcalá de Henares, en ejecución de una carta de marca decretada contra vecinos de Molina y su Tierra, con el argumento de que él era vecino de esta villa castellana ${ }^{8}$.

\section{CAMBIOS DE RESIDENCIA «DE LARGO RECORRIDO»}

La circulación de judíos entre las Coronas de Castilla y Aragón no se limitó, sin embargo, a traslados de residencia de corto radio entre lugares muy próximos a las fronteras. Por el contrario, la documentación nos proporciona testimonios de otros muchos que implicaron el recorrido de muy largas distancias, a veces no sólo por tierra, sino también incluso por mar. Es el caso de Toroz Vidal de Narbona, quien después de haber estado residiendo en el Castillo de Garcí Muñoz, en Castilla, pasó a fijar más adelante su morada, junto con su mujer y sus hijos, en la ciudad de Mallorca, donde sabemos que vivía en el año $1377^{9}$. Otro ejemplo en el mismo sentido nos lo proporciona Salamon Abenlup, judío de origen castellano que a fines de la década de 1370 residía igualmente en la capital balear y denunció ante el monarca aragonés que muchos judíos castellanos que habían pasado a residir en lugares de la Corona de Aragón le adeudaban dinero, y se negaban a pagar sus deudas ${ }^{10}$.

\footnotetext{
${ }^{8}$ ACA, C, reg. 428-278.

${ }^{9}$ ACA, C, reg. 795-36 Barcelona, 20-XII-1377.

10 ACA, C, reg. 805-61, Barcelona, 9-II-1379. En concreto, la denuncia presentada por este judío fue contra muchos judíos del reino de Castilla «ad terras et regna nostra declinantes». Sobre este mismo judío, vid. ACA, C, reg. 1440-33, Barcelona, 16-III-1379, publicado por F. BAER, Die Juden im christlichen Spanien. Urkunden und Regesten. Vol. I. Aragonien und Navarra (Berlin 1929) pág. 480. Guiaje para Salamon Abenlup, judío de Castilla, vecino de Mallorca, quien en 1378 había sido arrendador de impuestos en Murcia.
} 
Dentro del territorio peninsular fueron también muy frecuentes los cambios de residencia realizados por judíos entre los grandes centros mercantiles de las Coronas de Castilla y Aragón. Así, podemos destacar el caso de la ciudad de Burgos, el principal centro mercantil castellano del momento ${ }^{11}$, de donde procedían varios judíos instalados en ciudades aragonesas durante la segunda mitad del siglo XIV, como, por ejemplo, los hermanos Mahir el Levi y Samuel el Levi, hijos del judío burgalés Açach el Levi, el mayor, quienes en las últimas décadas del siglo XIV residían en la ciudad de Zaragoza, donde desarrollaban una importante actividad al servicio del monarca aragonés Juan I, quien los calificó como «familiares y buenos servidores» suyos ${ }^{12}$, o Iucef de Burgos, maestro de piedra de la casa de Pedro IV, quien se instaló en Calatayud procedente de Castilla hacia $1366^{13}$.

Del mismo modo que judíos burgaleses se trasladaron a residir en ciudades aragonesas, también disponemos de testimonios que prueban que en ocasiones tuvo lugar el fenómeno inverso, y judíos de origen aragonés fijaron su residencia en la ciudad del Arlanzón, como es el caso de Benvenist, vecino de ésta en 1383, quien era hijo de Iuce Benvenist, judío de Tarazona que había sido llevado a Castilla como esclavo durante la guerra de los dos Pedros ${ }^{14}$.

\footnotetext{
11 Sobre la importancia de Burgos como centro mercantil en el siglo XIV, vid. H. CASAdo Alonso, «Religiosidad y comercio en el siglo XIV. La cofradía de tenderos de paños de Burgos», en Poder y Sociedad en la Baja Edad Media Hispánica. Estudios en homenaje al profesor Luis Vicente Diaz Martin, ed. C. M. REGLERO DE LA FUENTE (Valladolid 2002) págs. 357-374.

12 ACA, C, reg.1867-20v, Barcelona, 15-VII-1387.

13 Se hace referencia a este cambio de domicilio en ACA, C, reg. 912-158, Calatayud, 27-V-1366, publicado por F. BAER, Die Juden, vol. I, doc. nº 274, pág. 390. Una hermana de este Iucef de Burgos, Clara, contrajo matrimonio poco después en la ciudad de Calatayud con un judío castellano, vecino de Almazán: Jacob Fariello. Noticia en ACA, C, reg. 748-18v, Valencia, 10-XII-1369.

${ }^{14}$ Véase ACA, C, reg. 836-121v, Monzón, 10-VI-1383. Comisión a García Muñoz de Pamplona, jurisperito y baile de Calatayud, para conocer de todas las causas que Benvenist siguiese contra vecinos de Tarazona, relacionadas con la reclamación de los bienes que le correspondían de la herencia de su padre.
} 
Por su parte, entre los grandes centros mercantiles de la Corona de Aragón que atrajeron a judíos de origen castellano se ha de destacar, a juzgar por las informaciones hasta ahora reunidas, la ciudad de Zaragoza, donde fijaron su residencia algunos mercaderes y financieros judíos de notable relieve procedentes de Castilla, entre los que podemos destacar a Samuel Benveniste, individuo originario de Soria que pasó a fijar su residencia en la capital aragonesa poco después de marzo de 1370, cuando el infante Juan le otorgó una carta de guiaje a fin de facilitar su traslado ${ }^{15}$. En efecto, éste, una vez consumado el traslado de domicilio, pronto logró integrarse en el selecto grupo de las familias de máximo rango social de la aljama zaragozana, constituido por las familias «francas» de «la Cavalleria» y «den Abnalazar», con las que llegó a establecer estrechos vínculos de parentesco ${ }^{16}$.

La movilidad, por otra parte, potenció la consolidación de estrechos vínculos de parentesco entre judíos residentes en ciudades de las Coronas de Castilla y Aragón, con frecuencia muy alejadas entre sí. Así, por ejemplo, sabemos que un judío toledano, Todroç el Levi, era pariente de Alazar Golluf, tesorero de la reina Violante de Bar, esposa de Juan I, uno de los judíos más destacados de la aljama de

${ }^{15}$ La carta de guiaje, fechada en 19-III-1370, en ACA, C, reg. 1678-84; noticia en F. BAER, Die Juden, vol. I, pág. 486. La primera referencia sobre su presencia como vecino en Zaragoza data, no obstante, de 1380 , lo cual no significa que el avecindamiento se hubiese producido en dicho año. La noticia aparece en una provisión de Pedro IV, otorgada en Barcelona, 21-IV-1380, que publica F. BAER, op. cit., pág. 486

${ }^{16}$ En Barcelona, 21-IV-1380, Pedro IV concedió a Samuel Benvenist, y Iucef, su nieto, y al resto de miembros de su familia que, a pesar de que había quedado prohibido que los judíos pecheros de la aljama de Zaragoza participasen con los judíos francos de la Cavalleria y den Abnalazar, «en bodas, circumcisiones, sepulturas e otras solemnidades», ellos pudiesen hacerlo, por haber emparentado con la familia de la Cavalleria. Pocos días antes, en Barcelona, 29-II-1380, este mismo monarca había dado autorización para que todos los judíos de la aljama de Zaragoza, tanto francos como pecheros, pudiesen participar en las celebraciones de la boda de Juçaf Benvenist, judío castellano y pechero (presumiblemente el nieto de Samuel identificado en el otro documento como Iucef), con la judía zaragozana Bonafilla, hija de Vidal dela Cavalleria. Vid. F. BAER, Die Juden, vol. I, nº 329 , págs. 485-486. 
Zaragoza ${ }^{17}$. Por referencias indirectas también nos consta que a mediados del siglo XIV un judío de Valencia, Benvenist Avincaceç, tenía parientes que residían en Sevilla, los cuales intercedieron para evitar que fuesen vendidos como esclavos en dicha capital andaluza unos judíos que viajaban en un leño en el que se transportaban mercancías del propio Benvenist Avincaceç, el cual fue capturado por castellanos cerca del puerto de Santa Eulalia, en los mares de Ibi$\mathrm{za}^{18}$. Y, por fin, para poner un tercer ejemplo, recordaremos que el judío cordobés Assach Abenamias contaba con varios parientes residentes en los dominios del rey de Aragón, los cuales en 1381 intercedieron ante éste para que solicitara al rey de Castilla que permitiese regresar a este reino a aquél, pues se había visto forzado a huir a Aragón hacía unos años por no poder responder de unos arrendamientos de rentas que había tenido a su cargo ${ }^{19}$.

La existencia de vínculos de parentesco entre judíos residentes en ciudades de las Coronas de Castilla y Aragón muy distantes entre sí contribuyó, sin duda, a reforzar las relaciones de solidaridad entre las comunidades judías de ambos reinos, que manifestaron un grado de fortaleza sorprendente para una época en que las distancias imponían importantes frenos a las relaciones entre los individuos. Así, desde esta perspectiva, nos ha llamado la atención comprobar cómo judíos residentes en diferentes reinos se esforzaron por mantener vivos los vínculos de parentesco que les unían acudiendo a reuniones familiares con ocasión de algún señalado acontecimiento, como por ejemplo la celebración de unas bodas.

Una reunión de este tipo tuvo lugar en Zaragoza en 1399, con motivo de la celebración de las bodas de un sobrino de Bonafos de la Cavallería, judío vecino de la capital aragonesa. Para asistir a dichas bodas acudieron desde Castilla Iuce Benvenist, Abraham Benvenist,

\footnotetext{
17 ACA, C, reg. 1868-192, Zaragoza, 6-VI-1388.

${ }^{18}$ ACA, C, reg. 644-117v, Valencia, 12-IV-1347. Carta de Pedro IV al rey de Castilla.

${ }^{19}$ ACA, C, reg. 821-13v, Zaragoza, 8-I-1381.
} 
su hermano, Iuce Abenamias y Samuel Pixcuer de Soria, y desde Navarra Samuel Benvenist, vecino de Tudela, a todos los cuales extendió el monarca aragonés una carta de seguro y guiaje, a fin de que pudiesen acudir salvos y seguros a la capital aragonesa «pro decorando nuptias» ${ }^{20}$. Y tenemos constancia, por otra parte, de que no se trató de un caso excepcional, pues el propio Fritz Baer nos informa de otras bodas que se celebraron en Zaragoza a las que asistió Salomo Halevi, judío vecino de Burgos ${ }^{21}$.

Del mismo modo que la solidaridad se manifestó en las alegrías, también lo hizo en las penas, según nos lo demuestran las frecuentes intercesiones ante los reyes de Áragón de judíos aragoneses en favor de judíos castellanos en dificultades, de las que da cuenta la documentación cancilleresca. Por poner un ejemplo, recordaremos la de Alazar Golluf en favor de su pariente, el toledano Todroç el Levi, para conseguir que éste pudiese regresar, tras siete años de ausencia, a Castilla, de donde se había tenido que ausentar por habérsele acusado del asesinato de otro judío ${ }^{22}$.

\section{POLÍTICA DE ATRACCIÓN DE LOS JUDÍOS POR LOS MONARCAS CASTELLANOS Y ARAGONESES}

Los cambios de residencia de judíos que conllevaban el abandono del reino de origen fueron sin duda mal vistos tanto por los monarcas castellanos como por los aragoneses, cuando eran ellos quienes

${ }^{20}$ ACA, C, reg. 2171-127v, Zaragoza, 13-V-1399.

${ }^{21}$ F. BAER, Die Juden, vol. I, pág. 486.

${ }^{22}$ En concreto, Alazar Golluf, regente de la tesorería de la reina de Aragón, doña Violante de Bar, se dirigió en primer lugar al marido de ésta, el rey Juan I, para que éste a su vez solicitase a su pariente el rey de Castilla el perdón para Todroç el Levi. Juan I accedió a su solicitud, dirigiendo poco después una carta al rey de Castilla, en la que manifestaba su gran interés en que se concediese el perdón solicitado, puesto que debido a los grandes servicios que Alazar Golluf les estaba prestando a él y a su mujer, la reina, sentía una especial afección hacia él y todos los suyos. La carta al rey de Castilla en ACA, C, reg. 1868-192 Zaragoza, 6-VI-1388. 
perdían por esta vía contribuyentes o súbditos que les prestaban apreciables servicios. A pesar de ello, unos y otros no sólo toleraron estas prácticas, sino que incluso en ocasiones trataron de potenciarlas, desarrollando una política de atracción de los judíos de los reinos vecinos hacia el suyo propio que, en el caso de los monarcas aragoneses, puede ser analizada con cierto detalle gracias a la abundante información que proporcionan sobre esta cuestión los registros de cancillería.

En efecto, éstos nos informan en primer lugar de la frecuente concesión por los reyes de Aragón a judíos castellanos que habían manifestado su intención de mudar su residencia a territorio aragonés de cartas de guiaje, que les proporcionaban plenas garantías de que no se les aplicarían las medidas de represalia dictadas contra súbditos del rey de Castilla ${ }^{23}$. Pero conviene advertir que en más de un caso su concesión fue asociada a la exigencia de un compromiso de avecindamiento en un lugar de la Corona aragonesa durante un período mínimo de años, con frecuencia fijado en diez, que conllevaba además la obligación explícita de pechar junto con el resto de judíos de dicho lugar desde el mismo instante en que fijase allí su

${ }^{23}$ Entre los numerosos ejemplos que nos proporcionan los registros de cancillería, destacaremos a título ilustrativo los siguientes: ACA, C, reg. 1181-8v, Perpiñán, 21-IX-1362. Carta de seguro para Tedroç Ebleni y Iucef Abzecurero de Godalalfaiar (¿Guadalajara?), judíos del reino de Castilla que iban a acudir próximamente a Zaragoza. ACA, C, reg. 917-228, Valencia, 15-X-1369. Noticia en F. BAER, Die Juden, vol. I, pág. 425. Carta de guiaje para Rabi Çach Lapapa y Doña Bellida, viuda de Mosse Quatorze, y sus hijos, judíos castellanos que han pasado a residir en Teruel. ACA, C, reg, 1666-80v, Valencia, 20-IX-1382. El rey de Aragón toma bajo su especial custodia a Açach Abenamias, quien deseaba trasladar su residencia desde Castilla a Calatayud. ACA, C, reg. 841-143, Gerona, 23-II1385. Guiaje a favor del judío castellano Iafuda Abentiminiel, que deseaba pasar a residir en territorio aragonés. ACA, C, reg.1244-9, Barcelona, 10-VI-1374. Carta de guiaje a favor de Iucef Aznueto y David, su hermano, judíos de Guadalajara. En este caso no se deja constancia de que tuviesen intención de fijar su residencia en la Corona de Aragón. Una visión de carácter general sobre la institución del «guiaje» en la Corona de Aragón se encontrará en I. BuRNS, «The Guidaticum Safe-Conduct in Medieval Arago-Catalonia: A Mini-Institution for Muslims, Christians and Jews», Medieval Encounters 1 (1995) págs. 51-113. 
residencia. Y, en efecto, con estas condiciones concedió, por ejemplo, Pedro IV cartas de guiaje en 1370 a los judíos Samuel Samell, vecino de Cuenca, y Samuel Çamela, vecino de Moya, quienes al parecer tenían intención de trasladar su domicilio a Molina de Aragón ${ }^{24}$. Lo cual pone bien en evidencia cómo el móvil económico o, si se quiere, fiscal fue factor principal inspirador de la política de atracción de judíos castellanos practicada por los monarcas aragoneses durante el siglo XIV.

Esta política no se limitó, por lo demás, a la concesión de simples cartas de guiaje, sino que en otras ocasiones se ofrecieron alicientes adicionales para el cambio de residencia a determinados judíos, mediante la concesión de otros privilegios. Y así lo atestigua el caso de Samuel Abençaçon, judío que pasó a residir de Soria a Calatayud hacia 1370, quizás identificable con el célebre poeta del mismo nombre.

De hecho los motivos que llevaron a este judío soriano a pasar a residir al reino de Aragón fueron de índole política, pues, al parecer, había apostado de forma decidida por apoyar al rey Pedro el Cruel y, por consiguiente, tras el asesinato de aquél por su hermanastro Enrique de Trastamara, tenía motivos más que sobrados para temer las represalias de este último, convertido en nuevo rey de Castilla ${ }^{25}$. A pesar de ello, Pedro IV manifestó tan decidido interés en atraerlo

\footnotetext{
${ }^{24}$ La carta de guiaje a Samuel Çamela, vecino de Moya, en ACA, C, reg.1230-7, Barcelona 3-VIII-1370. La de Samuel Samell, vecino de Cuenca, en reg.1230-85v, Montblanc, 16-XI-1370. A ambos se puso como condición que debían presentar fiadores ante el baile de Daroca o su lugarteniente, que garantizasen que durante los diez años siguientes pecharían con la aljama de Molina o de cualquier otro lugar del rey de Aragón. Resulta sintomático que otras cartas de guiaje otorgadas entonces por Pedro IV en favor de diversos cristianos vecinos de Moya no se incluyó ninguna cláusula que impusiese a los beneficiarios del guiaje el compromiso de pechar en algún lugar del reino de Aragón durante un período mínimo de diez años.

${ }_{25}$ Así se hace constar en ACA, C, reg. 1264-140v, Barcelona, 3O-VII-1379, publicado por F. BAER, Die Juden, vol. I, pág. 483. Se reconoce que Samuel Abençaçon, «judío que solía estar en Soria», debió de abandonar Castilla por haber tenido «la voç del rey don Pedro», y que, tras su marcha, Enrique II hizo donación de sus bienes a Alvar González de Ferrera y otros.
} 
hacia Aragón que no se limitó a otorgarle la habitual carta de guiaje, para evitar que se le aplicasen las medidas de represalia decretadas contra castellanos, sino que también le concedió un importante privilegio adicional. Así, para facilitarle el cobro de las cantidades de dinero que le adeudaban en Castilla gran número de personas, dispuso que en adelante se embargasen todos los bienes y mercancías de dichos deudores que se encontrasen en territorio de la Corona de Aragón. Para ello, bastaría con que Samuel Abençaçon presentase a los oficiales del rey los documentos notariales probatorios, a la vista de los cuales éstos deberían proceder de inmediato al embargo, aunque se estableció una importante excepción, al quedar prohibido que se aplicasen estas medidas contra aquellos castellanos que hubiesen obtenido carta de guiaje del rey de Aragón, aunque tuviesen contraídas deudas con el referido judío. Pero, además, se le impuso a éste como condición, para poder aprovecharse de dicho privilegio, que al menos la mitad de las cantidades de dinero que consiguiese recuperar de sus deudores castellanos la invirtiese en los dominios del rey de Aragón ${ }^{26}$. Por tanto, la inclusión de esta cláusula nos confirma una vez más que el principal móvil de los monarcas aragoneses al intentar atraer judíos castellanos hacia sus territorios era el económico.

En cualquier caso, las concesiones hechas a Samuel Abençaçon para facilitar su avecindamiento en Aragón fueron consideradas excesivas por muchos de los vasallos del monarca aragonés. Y en concreto así lo denunciaron los representantes de las aldeas de la Comunidad de Calatayud, que se lamentaron ante Pedro IV por los serios perjuicios que de las mismas se estaban derivando para los habitantes de aquella comarca. En efecto, se estaban tomando sus bienes a castellanos que durante los años de la guerra habían venido a residir en las aldeas de Calatayud, y, además, otros castellanos que hasta entonces habían solido llevar a vender a este territorio «viandas,

\footnotetext{
${ }^{26}$ Este privilegio fue concedido a Samuel Abençaçon por Pedro IV por carta otorgada en Tarragona, 2-V-1370. La hemos consultado en versión trasladada en ACA, C, reg. 760-138v, Zaragoza, 17-III-1372.
} 
ropas y otras mercaderías» habían dejado de acudir por miedo a que les fuesen embargados sus bienes. Por todo lo cual, atendiendo las quejas de sus propios súbditos, el monarca aragonés finalmente accedió en marzo de 1372 a suspender el privilegio concedido a Samuel Abençaçon ${ }^{27}$.

A pesar de ello, en los años siguientes continuó ofreciéndole su incondicional apoyo. Y así nos lo confirma en primer lugar la concesión en octubre de 1374 de una nueva carta de guiaje a favor suyo y de su mujer, hijos y compañía ${ }^{28}$, a la cual siguieron a lo largo de la segunda mitad de la década de 1370 sucesivas provisiones conminando a sus oficiales a que le prestasen el auxilio necesario para poder cobrar las cantidades que se le adeudaban tanto en Castilla como en Aragón ${ }^{29}$. Por fin, en 1379, nada más acceder al trono castellano su yerno Juan I, Pedro IV se apresuró a solicitarle que tuviese a bien conceder el perdón a este judío por las faltas que hubiese podido cometer contra su padre Enrique II, y le devolviese los bienes que le habían sido embargados por orden de éste ${ }^{30}$. Pero en la carta nada se dice sobre que Samuel Abençaçon tuviese intención de retornar a Castilla en caso de que se le concediese el perdón solicitado, como sugiere Baer, por lo cual presumimos que continuó residiendo en Calatayud.

El compromiso del monarca aragonés en la defensa de los intereses de este judío soriano que había optado por trasladar su residencia a Aragón fue grande, pero ello no significa, que su integración en la sociedad aragonesa estuviese exenta de dificultades. Por el contrario, el propio hecho de que el rey se viese impelido a tener que otorgar tantas provisiones en su defensa sugiere que entre sus

27 ACA, C, reg. 760-138v, Zaragoza, 17-III-1372.

28 ACA, C, reg. 772-166, Barcelona, 20-X-1374.

29 ACA, C, reg. 777-115v, Lérida, 15-V-1375; reg. 783-162 Monzón, 15-V1376; y reg. 1633-102v, Calatayud, 30-XI-1378.

30 ACA, C, reg. 1264-140v, Barcelona, 3O-VII-1379. Documento publicado por F. BAER, Die Juden, vol. I, pág. 483. 
oficiales había poca predisposición a hacerlas cumplir, y de hecho así se reconoció de forma explícita en algunas de ellas. Pero si esta falta de predisposición respondía al hecho de que era un judío originario de Castilla, o simplemente era consecuencia de su dedicación a la actividad del préstamo, es algo que de momento resulta imposible determinar con seguridad.

Por otro lado, los monarcas aragoneses del siglo XIV, para favorecer la instalación en sus reinos de determinados judíos procedentes de Castilla, también recurrieron a otros procedimientos, como el ofrecimiento de garantías de que no se procedería judicialmente por deudas contra ellos durante un período de tiempo ${ }^{31}$, o incluso la concesión del privilegio de la exención de impuestos. En concreto, entre los beneficiarios de este último tipo de merced estuvieron Jacob Mosse y Abrahim, dos judíos de origen castellano, que la recibieron en 1331 de Alfonso IV, siéndoles después confirmada por Pedro IV en $1360{ }^{32}$; y, más adelante, Iucef de Burgos, judío avecindado en Calatayud, que sirvió como maestro de piedra en la casa de este último monarca y recibió de él privilegio de exención de impuestos en 1366, aunque más adelante se vio obligado a retirárselo como consecuencia de la enconada resistencia que ofreció la aljama bilbilitana a admitirlo ${ }^{33}$.

${ }^{31}$ ACA, C, reg. 795-36, Barcelona, 20-XII-1377. Pedro IV concedió a Toroz Vidal de Narbona, judío que pasó a residir con su mujer e hijos del Castillo de Garcí Muñoz, en Castilla, a la ciudad de Mallorca, que no se pudiese proceder contra él por ninguna deuda durante un período de dos años.

${ }^{32}$ ACA, C, reg.703-36, Zaragoza, 6-VI-1360. Carta de Pedro IV a sus oficiales del reino de Aragón y al comisario de la aljama de judíos de Zaragoza, para que hagan observar el referido privilegio concedido por su padre, en virtud del cual dichos judíos quedaban exentos durante toda su vida del pago de «peyta questia», y cualquier otro impuesto regio.

${ }^{33}$ El privilegio de concesión de franqueza a Iucef de Burgos en ACA, C, reg. 912-158, Calatayud, 27-V-1366. Ha publicado el documento F. BAER, Die Juden, vol. I, doc. $\mathrm{n}^{\circ} 274$, pág. 390. Sobre la resistencia ofrecida por la aljama judía de Calatayud a observar el privilegio, vid. ACA, C, reg. 733-54, Zaragoza, 15-VI1367. Carta de Pedro IV a los adelantados y aljama de judíos de Calatayud, en la que les recuerda que ya por carta anterior, fechada en Zaragoza, 15-VI-1366, les 
Y, por fin, para facilitar el traslado a sus tierras de algunos judíos castellanos, los monarcas aragoneses llegaron incluso a dirigirse a las autoridades castellanas para solicitarles que no impidiesen el cambio de residencia a determinados individuos que habían manifestado su deseo de pasar a vivir a Aragón. Así, por ejemplo, nos consta que en 1369 Pedro IV solicitó a Alvar García de Albornoz que permitiese a Salamón Abolafia, vecino de Cuenca, trasladar su domicilio al reino de Aragón, según era su intención, pues este judío le había hecho saber que se temía que este caballero trataría de impedirle que abandonase la referida ciudad castellana, donde era en aquellos momentos la persona más poderosa ${ }^{34}$.

La mayoría de los judíos que los reyes de Aragón trataron de atraer hacia sus reinos fueron, a juzgar por las noticias que proporcionan los registros de cancillería, individuos dedicados a las actividades financieras, o al comercio. En este afán, no dudaron incluso en conceder carta de guiaje a individuos sospechosos de haber cometido delitos de carácter financiero en Castilla, y que se veían forzados por ello a huir de dicho reino. Así lo atestigua el caso del judío cordobés Assach Abenamias, quien «viéndose destruido» por no poder cumplir con algunos arrendamientos que había tomado a su cargo en Castilla, recurrió al monarca aragonés Pedro IV para que le acogiese en sus dominios, y éste accedió a concederle el solicitado asilo argumentando que entendía que este individuo no era culpable de ningún delito ${ }^{35}$.

Pero a veces también dieron facilidades para que se instalasen en sus dominios judíos dedicados a otras actividades. Y así nos lo demuestra el acuerdo al que llegó en 1371 Pedro IV con un judío de

había ordenado que observasen el privilegio de franqueza a este judío. Por reg. 913-109, nos consta, no obstante, que en respuesta a las presiones de la aljama Pedro IV accedió finalmente a revocar el privilegio de franqueza concedido a Iucef de Burgos.

${ }^{34}$ ACA, C, reg. 1551-13, Valencia, 10-VI-1369.

${ }^{35}$ Noticia en ACA, C, reg. 821-13v, Zaragoza, 8-I-1381. 
Alcalá de Henares, llamado Jahuda Abengadella, por virtud del cual le autorizó para que pudiese cavar en búsqueda de tesoros escondidos en el lugar de Bocairente y en la sierra de Mariola, estando siempre presente el baile general de Valencia, con condición de que entregase a la hacienda regia la mitad de los tesoros que encontrase, una vez descontados los gastos que se ocasionasen por razón de la búsqueda, pudiéndose quedar él con la otra mitad, y regresar con ella a su tierra de origen. Pero al mismo tiempo le garantizó que, si él y sus compañeros en la empresa de búsqueda de tesoros, que eran dos judíos de Toledo, Iucef Abenbivo y Abrahim Abengadella, y un cristiano vecino de Villena, Pero Morello, quisieran mudar su domicilio al señorío del rey de Aragón, les trataría como a vasallos y naturales suyos ${ }^{36}$.

$\mathrm{Si}$ por un lado los monarcas aragoneses del siglo XIV intentaron atraer a determinados judíos castellanos para que fijasen su residencia en sus dominios, por otro se esforzaron a su vez en impedir por todos los medios a su alcance que los judíos de sus ciudades se marchasen a residir en Castilla. Pruebas de este talante las encontramos ya en diversas actuaciones de Jaime II, como, por ejemplo, cuando en 1297 aplaudió el proceder de los judíos de la aljama de Daroca, que habían ordenado detener a su paso por dicha ciudad a un judío de Zaragoza llamado Iucef Abehandala, cuando éste se disponía a mudar su domicilio a Molina, y, además, se habían esforzado por convencerle de que se quedase a vivir en el reino de Aragón ${ }^{37}$.

Sin duda, una de las actuaciones que mejor pone de manifiesto el interés de los monarcas aragoneses del siglo XIV por evitar la salida de sus dominios de los judíos, y muy en particular la de aquellos que les prestaban señalados servicios financieros, es la de Juan I y su esposa Violante de Bar en 1391 en relación a un judío vecino de

${ }^{36}$ ACA, C, reg. 1085-131v, Valencia, 16-IX-1371.

${ }^{37}$ ACA, C, reg. 108-143, Lérida, 5-VI-1297. Carta del rey Jaime II a la aljama de judíos de Daroca, aprobando su actuación y animándoles a que continúen tratando de convencer al judío para que se quede. 
Zaragoza llamado Samuel Benvenist, que era originario de Soria. En efecto, ese año éste había pasado a resolver algunos negocios a Castilla, relacionados al parecer con el cobro de ciertas cantidades de dinero que allí le adeudaban diversas personas ${ }^{38}$. Tuvo la mala suerte, sin embargo, de que en el transcurso de su estancia en territorio castellano se desencadenaron en ese reino graves desórdenes que amenazaron la seguridad de los judíos, y como consecuencia, cuando ya se disponía a emprender el viaje de regreso a Zaragoza, para ponerse a salvo del peligro, se vio obligado a refugiarse en un castillo perteneciente al señorío del obispo de Osma, situado en la villa soriana de Cabrejas del Pinar. Desconocemos cuánto tiempo permaneció allí refugiado, pero debió de ser relativamente prolongado, porque el monarca aragonés, que según su propia declaración necesitaba urgentemente de sus servicios, terminó por impacientarse y dirigió sendas cartas al obispo de Osma para que le permitiese salir salvo y seguro de Castilla, escoltándole hasta la propia frontera para impedir que pudiese ser atacado ${ }^{39}$.

Al parecer, el obispo de Osma respondió que no tenía noticia de que tal judío se encontrase en su castillo de Cabrejas, pero que en cualquier caso lo comprobaría en una próxima visita que era su intención realizar a ese y a otros castillos de su obispado, ofreciéndole garantías de que, si en alguno de ellos se encontraba Samuel Benvenist, se lo entregaría al monarca aragonés salvo y seguro. Al mismo tiempo, no obstante, añadió el obispo en su carta que si el judío quería convertirse al cristianismo, tal decisión no debería

\footnotetext{
${ }^{38}$ Ya en 1387, el monarca aragonés intercedió ante el rey de Castilla en favor de este judío, a quien calificó como su vasallo y buen servidor de la reina Violante, su mujer, para que le fuesen pagadas las cuantías de dinero que le adeudaban en el reino de Castilla varios súbditos castellanos que no se mostraban dispuestos a pagar. ACA, C, reg. 1867-21 Barcelona, 15-VII-1387.

${ }^{39}$ ACA, C, reg. 1878-53v Zaragoza, 3-VII-1391. Carta de Juan I al obispo de Osma, en que justificó en los siguientes términos su decisión de interceder en favor de Samuel Benvenist: «Como nos hayamos menester el dicho judío, y queremos mucho recobrarlo en nuestra señoría».
} 
causar «desplacer» al rey de Aragón. Y de esta forma, veladamente, venía a dar a entender que, en efecto, se estaba planteando la posibilidad de su conversión.

La respuesta de la Corte aragonesa a estas insinuaciones del obispo oxomense fue airada, según ponen de manifiesto sendas cartas que le fueron enviadas por la reina Violante de Bar y por su marido el rey Juan I, fechadas en Zaragoza en los días 12 y 16 de julio de 1391, respectivamente. En ambas cartas, de contenido muy parecido, se exigió al obispo que procediese sin tardanza a entregar al judío, con el argumento de que, si era cierto que quería convertirse al cristianismo, podría hacerlo «con más devoción» cuando se encontrase de regreso en Aragón, puesto que allí podría tomar sus decisiones con mayor libertad. No disimularon los reyes de Aragón en estas misivas, por lo tanto, sus sospechas de que se estaba presionando a Samuel Benvenist, al igual que a otros muchos judíos residentes en Castilla, para que se convirtiesen al cristianismo, bajo la amenaza de hacer uso de la fuerza. Y por ello plantearon en términos radicales su exigencia de la inmediata devolución del judío, no tanto porque les preocupase garantizarle el derecho a profesar la religión que desease, sino más bien porque necesitaban que volviese a Aragón para que les continuase prestando sus irreemplazables servicios financieros ${ }^{40}$.

\footnotetext{
${ }^{40}$ La carta de Violante de Bar al obispo de Osma, fechada en Zaragoza, 12-VII1391, fue publicada por F. BAER, Die Juden, vol. I, nº 411, pág. 659. La de Juan I, fechada en Zaragoza, 16-VII-1391, en ACA, C, reg. 1878-71. En la misma fecha Juan I escribió otra carta al rey de Castilla para que ordenase al obispo la inmediata liberación del judío (ibid.). Y, por su parte, la reina Violante de Bar dirigió desde Zaragoza el 16-VII-1391 al arzobispo de Toledo una carta solicitándole que ordenase al obispo de Osma que entregase al judío. Ha publicado esta carta F. BAER, Die Juden, vol. I, nº 411, pág. 660. El texto de las cartas enviadas por Juan I y su esposa al obispo de Osma es en su mayor parte idéntico, lo que sugiere que el escribiente de la cancillería empleó un mismo modelo, aunque hay algunas variantes de detalle entre ambas versiones. La más importante es que en la carta de la reina Violante se informa al obispo oxomense de que le envía a su portero Jaime Sala para que le haga entrega de la persona de Samuel Benvenist, a quien califica de «judio nuestro propio». De aquí deducimos que era la reina la principal
} 
Desconocemos cómo se resolvió entonces este conflicto, pero en cualquier caso sí nos consta que Samuel Benvenist consiguió regresar a Aragón, y continuó profesando allí la religión judía. Y así nos lo confirma en concreto una carta que en diciembre de 1393 dirigió el monarca aragonés al castellano Enrique III. En ella le hacía saber que su padre, Juan I de Castilla, había otorgado en vida varias provisiones en favor de este judío para facilitarle el cobro de las cantidades de dinero que le adeudaban diversas personas en Castilla, pero que, a pesar de ello, no había conseguido cobrarlas por habérselo impedido los levantamientos que habían tenido lugar contra los judíos. Por esta razón, le volvió a solicitar una vez más que tomase las medidas necesarias para asegurar que el referido Samuel Benvenist cobrase cuanto antes todo lo que se le seguía adeudando en el reino de Castilla ${ }^{41}$.

\section{JUDÍOS CON INTERESES ECONÓMICOS AL OTRO LADO DE LA FRON- TERA}

Los cambios de residencia propiciaron que los judíos avecindados en ciudades de la Corona de Aragón mantuviesen intereses económicos, y a veces incluso también propiedades, en la Corona de Castilla, y viceversa. Ciertamente, la capacidad reconocida a los judíos para poseer bienes inmuebles en el reino de Castilla estuvo sometida a restricciones cada vez más severas a partir de finales del siglo XIII, sobre todo en lo que se refiere a tierras ${ }^{42}$, aunque sí les fue reconocida sin inconveniente la propiedad de otro tipo de bienes inmuebles en ámbitos urbanos, como casas, solares, molinos, batanes, tintes, lavaderos o tenerías. Y este tipo de bienes nos consta que en ocasiones incluso fueron poseídos por judíos que residían fuera del reino,

interesada en el regreso del judío, probablemente porque éste se encontraba directamente a su servicio.

${ }^{41}$ ACA, C, reg. 1885-38, Tortosa, 12-XII-1393.

${ }^{42}$ Véase F. BAER, Studien, pág. 71. 
en concreto en ciudades aragonesas, como es el caso, por ejemplo, de unos molinos en término de la ciudad de Soria, que en los últimos años del siglo XIII eran propiedad de Ysmael de la Portiella, vecino de Tarazona, a quien le fueron ocupados tras el estallido de la guerra entre Castilla y Aragón en 1295, según él mismo denunció cuando, después de acabada la misma, exigió su devolución en cumplimiento de lo dispuesto en los acuerdos de paz ${ }^{43}$.

Del mismo modo, en contrapartida, la posesión por judíos residentes en Castilla de bienes inmuebles en el reino de Aragón también está bien constatada, pudiéndose comprobar que no siempre se trató de individuos residentes en lugares muy próximos a la frontera, como nos testimonia el caso de Iucef Gallef, judío residente en la villa castellana de Sepúlveda, quien poseía unas casas en la judería de Calatayud, por las que siguió pleito a fines del siglo XIV contra Todroz Contesti, hijo de Salamon Contesti, y Gracia, su mujer, a quienes acusó de habérselas ocupado ${ }^{44}$.

Los factores que propiciaron la posesión de bienes inmuebles en un reino por judíos que residían en otro no suelen resultar fácilmente identificables mediante el análisis de la documentación disponible, pero es seguro que incidieron varios aparte de los cambios de residencia de los propietarios. Por ejemplo, nos consta que a veces algunos judíos adquirieron bienes inmuebles en otro reino gracias a habérseles cedido como garantía hipotecaria de un préstamo. $\mathrm{Y}$ en concreto fue por esta vía como una familia de judíos residente en Burgos adquirió en las últimas décadas del siglo XIII una heredad en Alagón, en el reino de Aragón. Así lo manifestó en 1330 Samuel Rabaxa, judío vecino de Burgos, quien informó que hacía mucho

\footnotetext{
${ }^{43}$ Véase ACA, C, reg. 136-215, Barcelona, 26-VIII-1305. Carta de Jaime II al juez y alcaldes de Soria, pidiéndoles que restituyan a Ysmael de la Portiella, judío de Tarazona, las dos muelas de molino que le tenían ocupadas Sancho Fernández de Sauquiello y Sancha Martínez de Barrionuevo, vecinos de Soria, en los molinos de La Hoz, en término de dicha ciudad.

${ }^{44}$ ACA, C, reg. 2113-121, Zaragoza, 6-III-1398. Comisión a Rabi Jona, judío de Calatayud, para que entienda en la referida causa.
} 
tiempo su padre, Iucef Ravaxa, había prestado a Abraham de la Cavalleria, judío de Zaragoza, seis mil sueldos jaqueses, por razón de los cuales éste había entregado a Mira, su madre, mujer de Iucef Ravaxa, una heredad que poseía en Alagón, que más tarde, al declararse la guerra entre Castilla y Aragón, fue embargada por el monarca aragonés, quien hizo donación de la misma a un judío llamado David Nascara, el cual luego a su vez la traspasó al caballero aragonés Juan Garcés de Alagón ${ }^{45}$.

Además de la posesión de propiedades inmuebles, otro factor que propició que los judíos castellanos y aragoneses tuviesen fuertes intereses económicos fuera del reino donde residían radicó en el propio carácter de sus actividades profesionales, entre las que ocuparon un lugar muy destacado el comercio y el préstamo. Para empezar, nos encontramos con que bastantes de los judíos que en el transcurso del siglo XIV cambiaron su residencia de la Corona de Castilla a la de Aragón, o viceversa, estuvieron dedicados a estas actividades, y como consecuencia continuaron manteniendo fuertes intereses económicos en sus reinos de origen durante prolongados períodos de tiempo después de su cambio de residencia. Cuando tomaron la decisión de emigrar, habitualmente debieron de dejar sin cobrar muchas deudas que habían contraído con ellos personas a las que o bien habían prestado dinero, o bien habían vendido mercancías a crédito. Y por ello, debieron continuar manteniéndose en contacto con las autoridades del reino del que se habían marchado, para intentar conseguir el cobro de estas deudas; esta tarea, por razones fácilmente comprensibles, con frecuencia estuvo plagada de dificultades.

Así les ocurrió, por ejemplo, a los hermanos Mahir el Levi y Samuel el Levi, judíos de origen castellano residentes en Zaragoza, quienes en 1387 denunciaron que los concejos de Santa María del Campo, lugar del señorío de Diego López de Estúñiga, y Mahamud, Presencio y Ciadoncha, lugares de señorío de Juan Hurtado de

${ }^{45}$ ACA, C, reg. 438-61v Barcelona, 29-III-1330. Carta de Alfonso IV a Juan Garcés de Alagón, a petición de Samuel Ravaxa. 
Mendoza, les estaban adeudando una cantidad próxima a los 80.000 mrs. por razón de ciertas cuantías de dinero que en su día había prestado a dichos concejos su padre, Açach el Levi, el mayor, que había sido vecino de Burgos. Tras muchos esfuerzos, dichos judíos habían conseguido que la Audiencia del rey de Castilla diese sentencia a su favor; por ella se conminaba a los concejos a que les hiciesen efectivas las cantidades adeudadas. Sin embargo, dicha sentencia no se pudo llevar a ejecución, según denunciaron los propios judíos, debido al favor del que Diego López de Estúñiga y Juan Hurtado de Mendoza gozaban en la Corte castellana. Por ello, ante la falta de perspectivas de que las autoridades castellanas les hiciesen justicia, recurrieron ante el propio rey de Aragón, para solicitarle que apremiase al monarca castellano a que ordenase llevar a ejecución inmediatamente la sentencia dictada por su propia Audiencia ${ }^{46}$.

Los hermanos Mahir y Samuel el Levi tuvieron que trabajar mucho para lograr cobrar unas deudas en Castilla que les correspondieron como parte de la herencia paterna. Pero otros muchos judíos de origen castellano que pasaron a residir en Aragón se vieron obligados a seguir frecuentando este reino para poder cobrar las cantidades que les adeudaban personas e instituciones castellanas por razón de préstamos que ellos mismos les habían efectuado, como bien atestiguan, entre otros, los casos de Samuel Abençaçon y Samuel Benvenist, judíos sorianos que pasaron a residir en Calatayud y Zaragoza respectivamente, a quienes ya nos hemos referido extensamente con anterioridad. Ahora bien, lo que no es seguro es que todas estas deudas se hubiesen contraído antes del traslado de su residencia al reino de Aragón, sino que en muchos casos es probable que se hubiesen originado en un momento posterior ${ }^{47}$.

${ }^{46}$ ACA, C, reg. 1867-20v, Barcelona, 15-VII-1387. Carta del rey de Aragón al rey de Castilla.

47 Así, como hemos indicado, Samuel Benvenist viajó en 1391 a la región soriana para tratar de cobrar ciertas deudas, pero cuesta creer que para fecha tan tardía éste continuase sin cobrar cantidades que se le adeudasen del tiempo en que había tenido fijada su residencia en Soria. 
Sef 63: 2 (2003) LA MOVILIDAD DE LOS JUDÍOS A AMBOS LADOS DE LA FRONTERA ENTRE... 261

En efecto, independientemente de los cambios de residencia de judíos de un reino a otro, una práctica muy arraigada entre los judíos residentes en ciudades próximas a la línea fronteriza entre Castilla y Aragón a lo largo de todo el siglo XIV fue la concesión de préstamos a vecinos e instituciones radicadas al otro lado de la frontera, a pesar de los evidentes riesgos que este tipo de actividad entrañaba, puesto que el cobro a deudores morosos planteaba muchas más dificultades cuando éstos residían en un reino distinto. Pero lo cierto es que, a pesar de ello, los judíos hispanos no tuvieron inconveniente en ocasiones en aceptar como medio de pago el traspaso del derecho de cobro de cantidades debidas por extranjeros. Y así nos lo pone de manifiesto el siguiente caso, del que nos informa un documento de la cancillería de Fernando de Antequera, que proporciona una magnífica ilustración de los procedimientos de compensación de deudas entre personas e instituciones ubicadas en distintos reinos que estaban en vigor en la Península a fines del siglo XIV y comienzos del $\mathrm{XV}$. En concreto, refiere dicho documento que un judío castellano vecino de Calahorra llamado Jacob Albella había efectuado un préstamo al concejo y jurados de Peralta, en el reino de Navarra, que quedó obligado a entregarle en cierto plazo quinientos florines de oro de Aragón. Más adelante, el judío traspasó el derecho a cobrar dicha deuda a otro judío aragonés llamado Açach Amato, vecino de Zaragoza, en compensación por deudas que con él tenía contraídas. Sin embargo, cuando este último envió un procurador suyo a Peralta para cobrar los quinientos florines, no consiguió que se los pagasen, por lo que una vez más se vio forzado a recurrir al socorrido procedimiento de presentar denuncia ante el rey de Aragón, para que éste a su vez reclamase ante el rey de Navarra el pago de la deuda ${ }^{48}$.

Las fronteras entre reinos no representaron, por lo tanto, relevantes obstáculos disuasorios para los judíos hispanos que en el siglo XIV se dedicaron a las actividades financieras. Fueron sobre todo aquellos que tuvieron fijada su residencia en ciudades ubicadas en

${ }^{48}$ ACA, C, reg. 2367-150v, Zaragoza, 22-III-1414. Carta del rey de Aragón, Fernando I, al rey de Navarra. 
comarcas fronterizas los que con mayor frecuencia se arriesgaron a invertir su dinero en préstamos a personas e instituciones radicadas fuera del reino en el que residían. Y es el análisis de la documentación generada por la cancillería aragonesa el que, a falta de un equivalente de este tipo de documentación en la Corona de Castilla, mejor nos permite comprobar la notable difusión de esta práctica.

En primer lugar, en efecto, dicha documentación demuestra que el número de judíos que efectuaron préstamos de dinero en la Corona de Aragón durante el siglo XIV fue muy crecido, aunque, por supuesto, los datos cuantitativos que puedan extraerse de un exhaustivo análisis de la misma han de ser tomados con extrema precaución, pues debe tenerse en cuenta que nos informa preferentemente sobre operaciones de préstamo que dieron lugar a litigios.

En segundo lugar, además, esta documentación pone de manifiesto que con notable frecuencia judíos avecindados en ciudades de Aragón muy próximas a la frontera con Castilla prestaron dinero a instituciones y personas particulares de este reino. Así, por ejemplo, disponemos de testimonios de préstamos efectuados por judíos de Tarazona en Ágreda y su entorno ${ }^{49}$; por judíos de Calatayud en otras villas castellanas muy próximas a la frontera, como Deza, Cihuela o Serón ${ }^{50}$; o por otros judíos con domicilio no determinado en la comarca de Molina de Aragón ${ }^{51}$. A estas referencias hay que sumar

\footnotetext{
${ }^{49}$ ACA, C, reg. 439-135, Teruel, 9-X-1330. El escudero Rodrigo González de Torres, vecino de Ágreda, manifestó que había tomado en préstamo, apremiado por la necesidad, ciertas cantidades de dinero de judíos vecinos de Tarazona, en condiciones usurarias, y con obligación de entregar en prenda algunos vestidos suyos y viñas y piezas de tierra en término de Tarazona.

50 ACA, C, reg. 619-101, Barcelona, 25-V-1342. Pedro IV ordena a Blasio de Aynsa que averigüe si ha intervenido usura en los préstamos efectuados por algunos judíos aragoneses a vecinos de Deza y Cihuela, e imparta justicia. ACA, C, reg.111-282v, Barcelona, 26-V-1298. Benvenist y Mosse, hijos de Abrahim el Rabi, judíos de Calatayud, denunciaron que varios vecinos de Serón que les debían dinero no les querían pagar.

51 ACA, C, reg.125-22v Monasterio de Sixena, 10-VIII-1302. Carta al justicia, jurados y concejo de Molina, recogiendo la denuncia presentada por Abrahim, judío físico súbdito del rey de Aragón, a quien adeudan dinero algunos vecinos de Molina que se niegan a pagarle.
} 
otras relativas a judíos avecindados en estas mismas ciudades aragonesas que efectuaron préstamos a castellanos, sobre los que desconocemos el lugar exacto de residencia ${ }^{52}$. Casi siempre se trató de préstamos de pequeña cuantía efectuados a personas particulares, pero en algunas ocasiones también se concertaron operaciones de mayor envergadura con instituciones de gobierno local, como por ejemplo el sexmo de Frentes, de la Universidad de la Tierra de Soria, que adeudaba en 1397 al judío bilbilitano Mossef Albi la cantidad de ochocientos florines de oro de Aragón ${ }^{53}$, o el concejo de la villa de Atienza, que tenía contraída una deuda hacia 1383 de cuantía no especificada con otro judío vecino de Calatayud, Salamon Abenduhet ${ }^{54}$. Y, por supuesto, los prestamistas no fueron individuos

\footnotetext{
52 Véase ACA, C, reg.1830-76, Barcelona, 8-X-1387. Todroz Avenalça, Abrahe, hijo de Iuce Pitagon, Soli y Garnile, en su propio nombre y como tutores de Abrahe, Içaque, Iuce y Ceti, hijos de Benvenist Arnet y de la dicha Garnile, todos judíos de Calatayud, denunciaron dificultades en el cobro de cantidades que se les debían por razón de préstamos, depósitos y comandas, por vecinos de Calatayud y sus aldeas, y de diversos lugares del reino de Castilla. ACA, C, reg.1843-28, Monzón, 1-XII-1389. Iucef Avencabra, físico de Calatayud, denuncia que no puede recuperar las cuantías de dinero que se le deben en Calatayud, Daroca y diversos lugares del reino de Castilla. ACA, C, reg.1858-182, Tortosa, 11-XII-1393. Sabat Çahadia y Oro su mujer, Salamon y Jamila su mujer; Salamon Alhazan y Mossef Alhazan, hijos de Salamon Alhazan, todos judíos de Calatayud, han de seguir pleitos para cobrar diversas cantidades de dinero que se les deben por razón de depósitos, comandas y préstamos en Calatayud y sus aldeas, Daroca y sus aldeas, por las universidades de aldeas de Calatayud y Daroca, por algunos lugares de señorío de nobles y caballeros, y, por fin, por algunos lugares de Castilla.

53 ACA, C, reg. 2119-69v, Zaragoza, 17-XII-1398. Se hace constar que Mossef Albibi, judío de la aljama de Calatayud, había obtenido sentencia del gobernador de Aragón, pronunciada en Calatayud 5-XII-1397, por la que condenaba a los hombres pecheros de todas las aldeas del sexmo de Frentes, en la Tierra de Soria, y a Vicente Pérez de Villaciervos, vecino de Villaciervos, Pascasio García de Herreros, vecino de Herreros, Domingo Fernández, vecino de Ortiellos (?), Pascasio Domíngues el Ruvio, vecino de Vinuesa, y Pascasio Muñoz, vecino de Cidones, a pagarle ochocientos florines de oro de Aragón, que éstos se habían obligado por instrumento público a entregarle, renunciando a la jurisdicción de sus propios jueces locales. Dado que el judío no había podido obtener satisfacción, el rey le concedió licencia para pignorar bienes de los pecheros del sexmo de Frentes hasta obtener satisfacción de la cantidad que se le debía.

54 ACA, C, reg. 828-163, Monzón 8-VIII-1383.
} 
especializados en la clientela castellana, sino que muchos de los que tomaron de ellos dinero en préstamo fueron súbditos aragoneses, en su mayoría campesinos avecindados en aldeas de las Comunidades de Calatayud y Daroca.

Este flujo de dinero por vía de préstamos efectuados por judíos aragoneses a súbditos del reino de Castilla fue compensado por otro igualmente importante en sentido contrario, resultado de préstamos que realizaron judíos castellanos a súbditos del rey de Aragón, de los que también abundan las noticias en la documentación cancilleresca. Así, disponemos de testimonios sobre préstamos efectuados por judíos de Molina en la comarca de Daroca ${ }^{55}$ e incluso en Teruel ${ }^{56}$, por judíos de Deza en la comarca de Calatayud ${ }^{57}$, y por judíos de Soria en la comarca de Ariza ${ }^{58}$.

\footnotetext{
${ }^{55}$ Referencias a los préstamos efectuados por Jahuda Azezech (otras veces llamado Jahuda Açanches), judío de Molina, en Daroca y sus aldeas, en ACA, C, reg. 131-109, Calatayud, 15-III-1304. Un ejemplo de fecha posterior en ACA, C, reg. 2145-163v, Perpiñán, 27-II-1406. Samuel Abenafia, judío de Molina, había denunciado que, encontrándose en Calatayud para proceder judicialmente contra varios vecinos de Villafranca, aldea de Daroca, que le debían dinero por instrumentos públicos, varios de éstos con palabras falaces le engañaron y llevaron a casa de Juan de Linyan, vecino de Calatayud, y allí le quitaron con suma violencia nueve cartas de deudas que sumaban cuatrocientos florines, y treinta y cinco florines de oro que llevaba consigo.

${ }^{56}$ ACA, C, reg. 142-253, Daroca, 25-X-1308. Salamon Noziell, judío de Molina, denunció que Juan Marcho de Valespesa, Miguel Fernández de Carrión y Pascasio Sánchez de Menestril, vecinos de Teruel, le debían por instrumento público cierta cantidad de mrs. de Castilla, que Juan Marcho de Valespesa estaba obligado a entregarle por razón de una fianza efectuada en favor de Sancho Izquierdo, vecino de Molina.

57 ACA, C, reg.666-13v, Perpiñán, 16-XI-1351. Infuda, judío de Deza, recaudador de los diezmos del reino de Castilla, había denunciado que muchos vecinos de Malanquilla, aldea de Calatayud, le debían ciertas cantidades de dinero, que no le querían pagar, amparándose en un privilegio de concesión de moratoria que habían obtenido del rey de Aragón.

${ }^{58}$ ACA, C, reg.777-116, Lérida, 14-V-1375. Carta dirigida a la justicia, baile y alamín de Ariza, en que se les informa que Samuel Gaon, judío de Soria, había denunciado que el baile general de Aragón trataba de impedirle el cobro de las cuantías que se le adeudaban en Ariza.
} 
Esta abundancia de noticias sobre préstamos realizados al otro lado de la frontera castellano-aragonesa por los judíos de los dos reinos que ésta separaba llama particularmente la atención si tenemos en cuenta que esta práctica conllevaba en la época un enorme riesgo, que, además, si ya de por sí era alto en períodos de paz, se incrementaba de forma extraordinaria en tiempos de guerra. Así, tenemos constancia de que, entre las medidas de represalia contra el enemigo que tanto los monarcas castellanos como los aragoneses tomaron cuando estaban en guerra entre sí, figuró la del embargo de las cantidades adeudadas en el propio reino a súbditos del monarca enemigo. De este modo, por ejemplo, durante la guerra entre Jaime II y Fernando IV, que se prolongó entre 1295 y 1304, sabemos que el primero ordenó que todas las cuantías de dinero que sus súbditos adeudasen a judíos vecinos de la ciudad castellana de Molina de Aragón fuesen cobradas por sus oficiales, y se ingresase el producto obtenido de su cobro en las arcas regias ${ }^{59}$. Más adelante, sin embargo, cuando ya estaba próximo el momento de la firma de la paz, el monarca aragonés concedió a alguno de dichos judíos, y muy en concreto a Jahuda Azezech, que pudiese volver a exigir el pago de las cantidades a él adeudadas en Aragón que le habían sido embargadas ${ }^{60}$. Esta decisión generó importantes conflictos en el momento de su aplicación, como bien atestigua una denuncia presentada por

\footnotetext{
${ }^{59}$ ACA, C, reg. 108-76, Lérida, 28-V-1297. Se hace referencia a una denuncia presentada por dos judíos vecinos de Daroca, Samuel Abendala y Salamon Azegeig, sobre abusos cometidos en la aplicación de esta norma.

${ }^{60}$ Así se hace constar en carta de Jaime II al justicia y jurados de Daroca, en ACA, C, reg. 131-109, Calatayud, 15-III-1304. Se nos informa, además, de que se había concedido esta merced al judío atendiendo una súplica del infante Juan, hijo de Alfonso X, y se aclara que, en principio, del importe total de las deudas confiscadas la hacienda del rey sólo se había quedado con una parte, y el resto había permanecido en poder de los deudores. También se informa de que la cantidad correspondiente a la hacienda regia del cobro de las cuantías de dinero que se adeudaban en Aragón a Jahuda Azezech se había entregado a Pedro Fernández y Pedro Pérez de Molina, para compensarles por la pérdida de bienes que habían dejado en Molina, tras decidir el traslado de sus domicilios a Aragón para entrar al servicio de Jaime II.
} 
los vecinos de las aldeas de Daroca, que acusaron a los jurados de esta ciudad de exigirles el pago de deudas que ya habían satisfecho a los diputados designados por Jaime II para recaudar los bienes confiscados a súbditos del rey de Castilla ${ }^{61}$.

Además del préstamo, otra actividad que propició que los judíos castellanos mantuviesen importantes intereses económicos en la Corona de Aragón, y, a la inversa, los judíos aragoneses en la Corona de Castilla, fue la práctica del comercio. En efecto, muchas son las noticias que proporciona la documentación sobre judíos que traspasaban la frontera terrestre castellano-aragonesa para comerciar con productos muy diversos en el vecino reino, unas veces para comprarlos, otras para venderlos, y en la mayoría de las ocasiones para realizar de forma simultánea ambas actividades. Pero conviene precisar que, a juzgar por las informaciones de las que hoy por hoy disponemos, la mayor parte de estos judíos fueron modestos mercaderes, o incluso a veces simples tenderos o buhoneros, y sólo en muy pocos casos alcanzaron la categoría de grandes mayoristas con elevado volumen de negocio.

Así, en primer lugar, los registros de pago del impuesto de la «quema» en la tabla de Zaragoza correspondientes a varios meses del año 1386 conservados en el Archivo de la Corona de Aragón ${ }^{62}$ nos ponen de manifiesto que un elevado número de judíos avecindados en pequeñas ciudades y villas de las comarcas castellanas más próximas a la frontera de Aragón, de las actuales provincias de Rioja y Soria, realizaban frecuentes viajes a este vecino reino para vender en él pequeñas cantidades de determinadas mercancías de las que

\footnotetext{
61 ACA, C, reg. 133-6v, Zaragoza, 18-VI-1304.

${ }^{62}$ ACA, MR (=Maestre Racional), leg. 2908, fols. 2 y 3. Se trata de dos registros correspondientes a tan sólo cuatro meses. Uno de ellos ha sido publicado y analizado por J. A. SESMA MUÑoz, «Zaragoza, centro de abastecimiento de mercaderes castellanos a finales del siglo XIV», Aragón en la Edad Media 13 (1997) págs. 125-158. Se trata, no obstante, del registro en el que sólo se da cuenta de salidas de mercancías de Aragón hacia Castilla. El otro, que no publica este autor, incluye tanto salidas como entradas.
} 
Castilla era excedentaria, y comprar a su vez allí otras que luego revendían en territorio castellano. En concreto, tenemos constancia de que a esta actividad se dedicaron judíos vecinos de Cornago, Cervera del Río Alhama, Enciso, Ágreda, Soria y Medinaceli, que llevaron a vender a Aragón cueros al pelo, queso, lienzos, margas, estopa y hierro, y trajeron de dicho reino para vender en Castilla paños de muy diversa procedencia, aceite, papel, pimienta, azafrán y otras especias ${ }^{63}$.

Los referidos registros también dejan constancia de la actividad desarrollada por otros judíos no residentes en comarcas fronterizas, o de los que simplemente se desconoce el lugar de residencia, como exportadores de mercancías de Aragón hacia Castilla. Entre ellos habría que destacar a varios vecinos de Burgos, como Sento, Açach, Jaco, Iuce, Iafuda y Abram Pardo, que en diversas partidas sacaron de Aragón una amplia gama de mercancías, entre las que destacaban los fustanes, las especias, y los productos de mercería y buhonería ${ }^{64}$. En la mayor parte de los casos tampoco se trató de partidas de gran volumen, aunque sí algo mayor que el habitual entre los judíos del anterior grupo, avecindados en lugares próximos a la frontera,

${ }^{63}$ A título ilustrativo, indicaremos que Soriano, judío de Medinaceli, metió en Aragón 43 cueros al pelo, 400 condos de lienzo, 23 condos de margas y 2 quintales de hierro. Abraham, judío de Cornago, sacó en una ocasión un paño de Berga, 5 arrobas de aceite y una onza de azafrán, y en otra 24 condos de paño de Berga y de la ciudad. Açach, judío de Cornago, metió en una ocasión 100 condos de margas y 3 piezas de estopa, y sacó en otra ocasión 8 condos de paños de Berga, y en otra 9 arrobas de aceite, 4 libras de pimienta y dos resmas de papel. Simuel, judío de Cornago, sacó 5 arrobas de aceite, 5 resmas de papel y 3 libras de pimienta. Iuce, judío de Cervera, sacó 28 condos de paño «sotil» de la ciudad, una libra de pimienta, una onza de azafrán y media arroba de aceite. Sento, judío de Cervera, sacó 19 condos de paño de la ciudad. Iuçe, judío de Enciso, metió 560 condos de margas, 80 condos de lienzo y 120 condos de estopa. Abraham, judío de Ágreda, sacó en una ocasión 4 condos de paño «sotil», y en otra un paño de Ripoll. Sento, judío de Ágreda, sacó en una ocasión 25 condos de paños, y en otra 15 condos de paños de Berga. Salamon, judío de Ágreda, sacó 6 condos de paño. Y Benvenist, judío de Soria, metió 160 cueros al pelo y 8 arrobas de queso. Todos los datos proceden de ACA, Maestre Racional, 2908-2.

${ }^{64}$ Todas las referencias a estos judíos se contienen en el registro publicado por J. A. Sesma MuÑoZ, «Zaragoza, centro de abastecimiento». 
por lo que es probable que estos judíos burgaleses fuesen mercaderes de mayor rango. Para confirmarlo, sin embargo, deberíamos contar con más elementos de información sobre estos individuos.

Un perfil semejante al de estos judíos burgaleses lo presentan otros varios correligionarios suyos de los que desconocemos el lugar de residencia, tales como Namias, Açach Abenamir, Simuel Enbito, Jaco Pisquer, Açach Corell, Simuel de Coriell, Ysach, Nombre Bueno y Salamo Caruxel, nombres a los que habría que añadir los de Baruc Çava de Molina, Açach de Haro y Iafuda de Sevilla; en ellos, la presencia del apellido toponímico proporciona una pista fiable sobre su lugar de procedencia. Sospechamos que todos estos individuos eran mercaderes profesionales, y quizás en algunos casos tratantes al por mayor, que se encargaban de proveer a otros mercaderes y a tenderos y regatones. No obstante, dado que apenas disponemos de más datos referentes a ellos, no lo podemos afirmar con absoluta seguridad. De cualquier modo, todo apunta a concluir que no se trataba en ningún caso de ambiciosos hombres de negocios, dedicados a la especulación y a la inversión a gran escala en la compraventa de mercancías, sino que tenían un rango más bien modesto.

Además de Zaragoza, otro núcleo urbano de la Corona de Aragón que ejerció gran poder de atracción sobre los judíos castellanos dedicados a la actividad mercantil durante el siglo XIV fue Valencia. Así lo demuestra, por ejemplo, el registro de cosas vedadas del año 1381, que deja constancia de la presencia en esta ciudad de judíos vecinos de Soria, Molina de Aragón y Cuenca, que adquirieron allí variados productos metálicos y de mercería, para exportarlos a Castilla ${ }^{65}$. Otros documentos cancillerescos, por su parte, nos informan de la participación de judíos castellanos en actividades de marcado

\footnotetext{
${ }^{65}$ Véase M. ${ }^{a}$ D. Cabanes Pecourt, Coses vedades en 1381 (Valencia 1971). Por ejemplo, Jacob de Soria pasó de Valencia a Castilla 50 dedales, 1.600 agujas de coser, 50 agujas de apuntar paños, 6 docenas de aguijones de lezna, 4 docenas de cuchillos, media grosa de botones de latón y 2 grosas de anillos. Salamo de Molina 10 pares de cardas, 4 grosas de botones de latón y 16 docenas de sortijas. Y Jacob Frances, judío de Cuenca, 2 tijeras de recortar, unas tijeras de sastre y 2.000 agujas.
} 
carácter especulativo en la ciudad del Turia, como era, por ejemplo, el comercio con metales preciosos, en concreto con plata ${ }^{66}$.

Además de estas informaciones puntuales, algunos otros indicios nos confirman que la afluencia de judíos castellanos a Valencia para practicar el comercio fue importante. Por ejemplo, sabemos que en 1327 los arrendadores de la tabla del peso de esta ciudad denunciaron que habían resultado fuertemente perjudicados por haber autorizado el rey a la aljama de los judíos a establecer una nueva imposición en su seno, puesto que como consecuencia de ello los judíos castellanos habían dejado de acudir con sus mercancías a la capital del Turia para evitar tener que pagar el referido impuesto. Atendiendo a esta denuncia, el rey ordenó al baile general de Valencia que averiguase si era cierto que, como consecuencia del cese de la llegada de judíos castellanos a esta ciudad, habían disminuido los derechos de la tabla del peso, para que, en caso de comprobarse que así había ocurrido, en adelante se eximiese a los judíos castellanos de la obligación de contribuir en la nueva imposición aprobada por la aljama valenciana ${ }^{67}$.

Por otra parte, del mismo modo que los judíos castellanos se desplazaron con regularidad a ciudades de la Corona de Aragón para practicar el comercio, también lo hicieron los judíos súbditos del rey de Aragón para hacer lo propio en territorio de la Corona de Castilla. A juzgar por las noticias reunidas, que no han sido muchas, parece que en su mayor parte se trató de modestos negociantes, residentes en ciudades próximas a la frontera, que en bastantes casos practicaban un comercio minorista de carácter ambulante. A este perfil, por ejemplo, responde el judío bilbilitano Jucef Benvenist, quien denunció que en 1372 unos castellanos procedentes de la fortaleza de Vozmediano (Soria) le robaron, cuando viajaba desde

${ }^{66}$ ACA, C, reg. 1081-125, Valencia, 11-IX-1369. Pedro IV ordena a Laurencio Terrats que tenga secuestrada hasta nuevo aviso toda la plata que había comprado un judío castellano en la ciudad de Valencia para sacarla del reino.

${ }^{67}$ ACA, C, reg. 250, s.f, Barcelona, 8-VII-1327. 
Calatayud hacia el reino de Castilla, 115 onzas de hilo de oro, 30 libras de azafrán, 4 piezas de fustán, 10 cajas llenas de confites, y un paño de Ripoll ${ }^{68}$. Pero también tenemos constancia de que otros judíos súbditos del monarca aragonés se involucraron en actividades mercantiles más ambiciosas en territorio castellano. Este sería el caso de dos judíos vecinos de Barcelona, B. de Viana y D. Astruch, quienes en la última década del siglo XIII sabemos que recibieron en comanda ciertas mercancías de dos cambiadores vecinos de esa misma ciudad, Guillermo Pérez de Usay y Pedro Zapata, para que las llevasen a vender en los reinos de Aragón y Castilla en el viaje que tenían intención de realizar a estos territorios, y empleasen el dinero obtenido de su venta en la compra de otras mercancías, que habrían de entregar a aquéllos a su regreso a Barcelona ${ }^{69}$.

\section{LAS GUERRAS ENTRE CASTILLA Y ARAGÓN Y SUS EFECTOS SOBRE LA SITUACIÓN DE LOS JUDÍOS}

Los frecuentes intercambios de bienes y personas entre los territorios de las Coronas de Castilla y Aragón que podemos constatar durante el siglo XIV, en los que, como hemos visto, tuvieron un relevante protagonismo los miembros de la comunidad judía, se produjeron, paradójicamente, en un marco de muy difíciles relaciones políticas y diplomáticas entre las dos monarquías. Las guerras entre los dos reinos se prolongaron, en efecto, durante muchos años, y en algunos momentos llegaron a alcanzar notable virulencia, en especial a raíz de la ocupación por las tropas castellanas del rey Pedro el Cruel de extensos territorios en Aragón y Valencia a mediados del siglo.

Para concluir nuestro estudio sobre la movilidad de los judíos entre los reinos de Castilla y Aragón, hemos considerado necesario, por tanto, dedicar brevemente nuestra atención a comprobar en qué

${ }_{68}$ ACA, C, reg. 766-23, Barcelona, 3-I-1373.

${ }^{69}$ ACA, C, reg. 102-167v Barcelona, 9-XII-1295. Guillermo Pérez de Usay y Pedro Zapata habían denunciado que hacía unos cinco años que habían entregado las mercancías a los dos judíos, según constaba por instrumentos notariales, pero éstos no habían regresado todavía a Barcelona de su viaje. 
modo la misma se vio afectada por la realidad bélica, la cual no puede ser ignorada en una visión global sobre el siglo XIV hispano. Desde esta perspectiva, hemos de llamar la atención, en primer lugar, sobre el hecho de que, en contra de lo que la asunción del mito del «judío apátrida» nos podría llevar a pensar, cuando estallaron conflictos entre los monarcas castellanos y aragoneses durante este siglo, bastantes judíos, en lugar de refugiarse en una posición de neutralidad, asumieron un fuerte compromiso político, apoyando a una de las partes contendientes.

Un primer testimonio lo encontramos en la trayectoria del judío soriano Samuel Abençaçon, quien, según ya hemos adelantado, por razón de su fuerte compromiso en apoyo de la causa del rey Pedro el Cruel, debió tomar el camino del exilio tras la muerte de este monarca a manos de su hermanastro Enrique de Trastamara, quien, en represalia, hizo embargar todos los bienes que dejó tras de sí en Castilla ${ }^{70}$. Y otro judío que también mantuvo una firme actitud de lealtad al rey Pedro el Cruel, incluso después de su muerte, fue Samuel Abolafia, vecino de Molina, quien desempeñó un papel de primera fila entre los representantes de esta villa que negociaron en 1369 su entrega a Pedro IV de Aragón, para evitar que pudiese adueñarse de ella Bertrand Du Guesclin, el capitán de mercenarios francés que había sido principal aliado de Enrique de Trastamara. En honor a la verdad, sin embargo, se ha de hacer constar que, además de su lealdad a la memoria del rey Pedro, y del temor a caer en poder de Enrique de Trastamara, otro importante factor contribuye a explicar su toma de postura en favor del rey de Aragón en 1369. Este no es otro que los numerosos privilegios que a él y a otros miembros de su familia les concedió como premio por la colaboración prestada ${ }^{71}$.

${ }^{70}$ ACA, C, reg. 1264-140v, Barcelona, 3O-VII-1379, publicado por F. BAER, Die Juden, vol. I, pág. 483.

${ }^{71}$ Muchos de los documentos que contienen mercedes de Pedro IV a Samuel Abolafia y su familia han sido publicados por L. BENÍTEZ MARTín, Documentos para la historia de Molina en la Corona de Aragón: 1369-1375. (El registro 1551 de la cancillería de Pedro IV) (Zaragoza 1992). En concreto, hay que destacar los siguientes. Doc. $\mathrm{n}^{\circ} 8$, Valencia, 5-VI -1369. Merced del «portado e del peso e de las paladas» de Molina hasta en cuantía 2.000 mrs. anuales. Doc. $n^{\circ}$ 9, Valencia, 5-VI-1369. Nombramiento de Sa- 
En cualquier caso, la relación de estrecha colaboración en el terreno político que se estableció entre Samuel Abolafia y el rey Pedro IV de Aragón propició que éste recurriese a sus servicios para el desempeño de otras delicadas misiones diplomáticas, que tendrían como probable objetivo tratar de convencer a los gobernantes de las ciudades y villas de la Castilla oriental de que siguiesen el ejemplo de Molina y se incorporasen voluntariamente a la Corona de Aragón. Así, en concreto, tenemos constancia de que a fines del año 1370 le encargó negociar cierto asunto con el concejo de Moya, y con dos vecinos de esta villa conquense en particular, Simón Fernández y Fernán Gutiérrez ${ }^{72}$. Pero, al mismo tiempo, para captar apoyos adicionales en estas comarcas fronterizas, este monarca también recurrió a otros judíos castellanos vecinos de las mismas, como, por ejemplo, los hermanos Samuel y Iuce Abravalla, vecinos del Castillo de Garcí Muñoz, y Samuel Cohen, vecino de Cuenca, a los que en octubre de 1369 concedió carta de guiaje para que pudiesen acudir a su presencia a tratar algunos negocios que, según propia confesión, «son servicio nuestro» ${ }^{73}$.

En la Corona de Aragón también se dieron casos relevantes de judíos que mantuvieron durante los años de guerra una actitud de

muel Abolafia como recaudador general de las rentas reales en Molina. Doc. $n^{\circ} 11$, Valencia, 5-VI-1369. Pedro IV absuelve a Samuel Abolafia, y a Mair y Abrahim Abolafia, sus hermanos, de la obligación de entregar los 80 cahices de pan que adeudaban a Ruy Gutiérrez de Sigüenza, cogedor que fue del rey Pedro de Castilla. Doc. $n^{\circ} 12$, Valencia, 5-VI-1369. Privilegio de exención de impuestos (pechas, sisas y pedidos) para Samuel Abolafia y el hijo suyo que desee designar, y para Mahir y Abrahim, sus hermanos, y Iuce Abolafia, hijo de Mail, y Mosse el nieto, su sobrino, y rabi Iusseff. También les concede «que podades prestar a logro segunt el coto e ordinación nuestra d'Aragón». Por fin, consta igualmente que se le había concedido para él y sus descendientes el oficio de «rab e oydor de los pleytos e questiones de los judios» de Molina, por referencia que se hace al privilegio en doc. $\mathrm{n}^{\circ} 45$, Valencia, 14-VIII-1371.

72 ACA, C, reg. 1230-83, Montblanc, 16-XI-1370. Carta de creencia a favor de Samuel Abolafia, dirigida por Pedro IV al concejo de Moya y a Simón Fernández y Fernán Gutiérrez.

73 ACA, C, reg. 1223-51, Valencia, 21-X-1369, publicado por F. BAER, Die Juden, vol. I, doc. $\mathrm{n}^{\circ} 295$, pág. 430. 
inquebrantable lealtad hacia su rey. Un buen ejemplo nos lo proporciona Gento de Narbona, judío vecino de La Almunia de Doña Godina, a quien el monarca castellano Pedro I intentó ganarse para su causa cuando invadió las tierras aragonesas, prometiéndole que le devolvería todos los bienes que le había tomado en Calatayud y sus aldeas, La Almunia, y Ricla, si entraba a su servicio. Éste, sin embargo, rechazó el ofrecimiento, prefïriendo continuar bajo el dominio del rey de Aragón, para lo cual trasladó su residencia a la ciudad de Zaragoza. Y por ello, finalmente, este último le recompensó mediante la concesión en junio de 1360 del privilegio de exención de impuestos a título personal para el resto de sus días, merced que en diciembre de 1363 hizo extensiva a todos sus descendientes, siempre que permaneciesen al servicio de los reyes de Aragón ${ }^{74}$.

No todos los judíos aragoneses, sin embargo, adoptaron una actitud de semejante lealtad a su rey en los difíciles tiempos de la guerra. Por el contrario,tenemos constancia de que algunos de ellos no se resistieron a la tentación de cambiar de bando. Así, por ejemplo, recordaremos que esto es lo que hizo, poco después de declararse la guerra en 1356, el judío bilbilitano Iaco Catorze, quien se apresuró a pasarse al bando del rey de Castilla, precipitando así la confiscación de sus bienes en Aragón, y en concreto de sus casas en la judería de Calatayud, por orden de Pedro IV ${ }^{75}$. En cualquier caso, ésta no fue una forma de proceder exclusiva de los judíos, sino que también incurrieron en ella bastantes cristianos, en particular en los años en que extensos territorios del reino de Aragón pasaron a quedar bajo dominio efectivo del monarca castellano.

El compromiso político de algunos judíos en los períodos de guerra entre Castilla y Aragón también se tradujo, por otro lado, en el frecuente desempeño por su parte de misiones diplomáticas, en su

${ }^{74}$ Véase. F. BAER, Die Juden, vol. I, doc. nº 265, págs. 373-5. Privilegio otorgado por Pedro IV en Barcelona, 6-XII-1363, que confirma y amplía uno anterior otorgado en Zaragoza, 23-VI-1360.

75 Noticia en ACA, C, reg. 1155-65v, Cariñena, 6-VIII-1357. 
mayoría de carácter secreto. Ya en el contexto de la guerra entre Jaime II y Fernando IV, a principios del siglo XIV, tenemos noticia de la actuación de individuos de esta religión como espías al servicio de estos monarcas. Como ejemplo testimonial baste recordar el caso de Azmel de la Portiella, cuyas actuaciones, no obstante, están documentadas sólo en el momento en que se estaba negociando la firma de la paz entre los dos reinos.

En efecto, por una carta de Jaime II, fechada el 31 de mayo de 1304, sabemos que éste había estado en Castilla junto con García Martínez de la Figuera, de donde ambos habían traído información al monarca aragonés, quien inmediatamente encargó a Azmel de la Portiella que emprendiese de nuevo viaje a ese reino para recabar nuevas informaciones ${ }^{76}$. Nada del contenido de esta carta permite, sin embargo, sospechar que su misión hubiese tenido un carácter secreto, pero otra que le dirigió pocos días después este mismo monarca lo sugiere de forma mucho más abierta. En efecto, en ella le pidió que viajase a Burgos para recabar información sobre el contenido de los acuerdos a los que pudiesen llegar Diego López de Haro y el infante Juan con el gobernador de Navarra, en las vistas que tenían previsto celebrar, pero le insistió en que desistiese de realizar el viaje en caso de que considerase que podría poner en peligro su persona ${ }^{77}$.

Fue, sin embargo, durante la llamada guerra de los dos Pedros, a mediados del siglo XIV, cuando, a juzgar por los indicios reunidos, más proliferaron las misiones de espionaje realizadas por judíos. Así, por ejemplo, sabemos que en 1365 Pedro IV llegó a sospechar del zaragozano Salamon de la Cavallería, porque había enviado a otro judío llamado Vidal, que era familiar y doméstico suyo, a Castilla, sin haber pedido licencia para poder hacerlo ni a él ni a sus

\footnotetext{
${ }^{76}$ ACA, C, reg. 235-79, Zaragoza, 31-V-1304, publicado por F. BAER, Die Juden, vol. I, doc. nº 153, pág. 177.

77 ACA, C, reg. 235-86, Zaragoza, 10-VI-1304, publicado por F. BAER, Die Juden, vol. I, doc. nº 153, pág. 177.
} 
oficiales. Sus sospechas se vieron además reforzadas por el hecho de que el referido Vidal había permanecido durante bastante tiempo en lugares de Castilla donde entonces se encontraba el rey Pedro I, luego regresó a Zaragoza, para hospedarse en la casa de Salamon de la Cavallería, y poco después fue de nuevo enviado a territorio castellano por este último. A juicio del rey de Aragón eran, por tanto, muchos los indicios que apuntaban a que Salamon de la Cavallería pudiese estar realizando «tratos siniestros contra nuestra Corona». Por ello, ordenó a su consejero, el doctor en leyes Pedro Terreni, que averiguase la verdad sobre este asunto, recurriendo, si fuese necesario, a someter a tormento al propio Salamon de la Cavallería para que confesase ${ }^{78}$. Por desgracia, desconocemos cuál fue el resultado de su inquisición y, por tanto, no podemos afirmar con certeza que este judío zaragozano fuese efectivamente un espía y un conspirador. Pero consideramos que el propio hecho de que sus actuaciones despertasen fuertes sospechas en Pedro IV constituye un indicio muy sintomático sobre cuál era el estado de ánimo dominante en la Corte aragonesa en aquellos momentos.

Comprensiblemente, quienes mayores sospechas despertaron en las autoridades aragonesas fueron los judíos de origen castellano que durante los años de la guerra deambularon por territorio de la Corona de Aragón. En ocasiones, nos consta que dichas sospechas estuvieron infundadas, como lo prueba el caso de Naçan de Molina, judío oriundo de Castilla. En efecto, sabemos que, encontrándose éste en el año 1362 en la comarca del Berguedá en Cataluña, fue detenido y despojado por el vicario de Berga y Berguedá de un instrumento musical y otros bienes que llevaba consigo, acusado de ser un espía («exploratorem») del rey de Castilla. Poco después, sin embargo, se pudo comprobar que se trataba de un simple juglar que hacía tiempo que se encontraba en territorio de la Corona de Aragón, donde había acudido en el séquito de Enrique de Trastamara ${ }^{79}$.

${ }^{78}$ ACA, C, reg. 1076-79, Tortosa, 17-I-1365

${ }^{79}$ ACA, C, reg.1180-49. Barcelona, 1-VIII-1362. Carta de Pedro IV a Guillem de Palacio, vicario de Berga y Berguedá y a otros oficiales, ordenándoles que devolviesen los bienes que hubiesen tomado al referido juglar judío. 
No todos los sospechosos resultaron, sin embargo, finalmente inocentes. Así, por ejemplo, tenemos certeza de que un judío castellano llamado Açach desempeñó misiones de espionaje para el rey Pedro I de Castilla en Zaragoza, a comienzos de la década de 1360. Para desarrollar mejor su actividad, contó con la colaboración que le prestó otro judío originario de Castilla que entonces residía en la capital aragonesa, Todros Levi, quien lo tuvo oculto en su casa durante cierto tiempo. Como consecuencia, el propio Todros Levi fue después procesado por la autoridades aragonesas acusado de traición, y se le condenó a pena de destierro del reino de Aragón, aunque finalmente obtuvo el perdón en julio de 1364, en consideración a que no había actuado con mala intención, sino sólo por ignorancia ${ }^{80}$.

En esta época, no obstante, los judíos no sólo tomaron parte en arriesgadas misiones de carácter secreto, sino que los monarcas castellanos y aragoneses también recurrieron en ocasiones a ellos para que les sirviesen como embajadores plenamente acreditados. Así, por poner algunos ejemplos, recordaremos que en 1312 el infante castellano Don Pedro envió a su suegro Jaime II a su almojarife, el judío don Çag, para tratar sobre cierto negocio ${ }^{81}$. Algunos años antes el propio monarca castellano, Sancho IV, había encomendado a un judío de su Corte, don Samuel, la misión de establecer contactos con el rey de Aragón y organizar una entrevista entre ambos ${ }^{82}$. Por su parte, el rey Pedro IV de Aragón también encargó a algunos judíos de su entorno el desempeño de misiones diplomáticas en Castilla, aunque a un más bajo nivel, como cuando envió hacia septiembre de 1367 a Moya a un tal Baru para resolver ciertos negocios no especificados en la carta de guiaje que entonces le otorgó ${ }^{83}$.

${ }^{80}$ La concesión del perdón por Pedro IV a Todros Levi, en ACA, C, reg. 167889, Zaragoza, 27-VII-1364. Ha publicado el documento F. BAER, Die Juden, vol. I, doc. n 271, pág. 387.

${ }^{81}$ F. BAER, Die Juden, vol. I, doc. nº 165 , págs. 203-4. Carta del infante Pedro a Jaime II, fechada en Almazán, 4-II-1312.

82 J. Zurita, Anales de la Corona de Aragón (Zaragoza 1967-86) vol. 2, pág. 404.

${ }^{83}$ ACA, C, reg. 1218-11, Zaragoza, 15-IX-1367. 
Sef 63: 2 (2003) LA MOVILIDAD DE LOS JUDÍOS A AMBOS LADOS DE LA FRONTERA ENTRE... 277

Por contraste con esta intensa participación judía en actividades diplomáticas, apenas disponemos de noticias sobre la intervención directa de individuos de esta religión en acciones bélicas. Todos los indicios apuntan a sospechar que los ejércitos que combatieron en las guerras entre Castilla y Aragón durante el siglo XIV estuvieron constituidos en su mayor parte por cristianos. Algún testimonio aislado confirma, no obstante, que individuos de religión judía tomaron parte activa en relevantes acontecimientos bélicos, aunque no podemos afirmar con absoluta certeza que lo hiciesen en calidad de combatientes armados. Así, por ejemplo, nos consta que Gento de Narbona, judío vecino de La Almunia de Doña Godina, comenzó sirviendo al monarca aragonés Pedro IV en la guerra de Cerdeña, a la que acudió formando parte del grupo que llevó consigo el noble Juan Martínez de Luna, y después participó en la batalla de Araviana contra el rey de Castilla, por lo cual en junio de 1360 este monarca, en premio a sus servicios, le hizo una merced, declarándole exento del pago de impuestos para el resto de sus días ${ }^{84}$.

La escasa participación de los judíos en las acciones militares, derivada de su escasa o nula integración en los ejércitos combatientes, tuvo como principal consecuencia que los miembros de este grupo, al igual que los mudéjares, sufriesen todas las consecuencias negativas de las guerras entre príncipes cristianos, sin apenas beneficiarse de las «compensaciones» que éstas podían ofrecer en la forma de obtención de botín, pues éste quedaba reservado para los soldados que combatían, o que saqueaban y robaban a los súbditos del enemigo. Y de ahí que los miembros de estas dos comunidades residentes en las comarcas fronterizas hayan de ser considerados como las principales víctimas de los conflictos entre los ejércitos de los reyes de Castilla y Aragón durante el siglo XIV. De hecho, para muchos de ellos la guerra, además de graves perjuicios económicos, también conllevó la pérdida de la condición de hombres libres.

\footnotetext{
${ }^{84}$ El privilegio de merced le fue otorgado por Pedro IV, en Zaragoza, 23-VI-1360. Ha sido publicado por F. BAER, Die Juden, vol. I, doc. nº 265, págs. 373-375.
} 
En efecto, en las guerras que tuvieron por escenario el espacio peninsular durante los siglos bajomedievales fue práctica muy frecuente la de convertir en cautivos a los súbditos del enemigo que se conseguía apresar. Pero, para los cristianos que eran apresados por otros cristianos en estas operaciones, el peligro de convertirse en auténticos esclavos era prácticamente inexistente, pues estaban muy arraigados los escrúpulos de conciencia que impedían vender como esclavos a individuos de la misma religión, aunque hubiesen sido capturados en guerra. Y así lo atestigua un caso ocurrido en Tudela en el año 1357, poco después de haberse declarado las hostilidades entre los reinos de Castilla y Aragón, que fue denunciado por unos vecinos de Zaragoza. Informaron éstos entonces que, encontrándose ellos en esta ciudad navarra, acudieron allí algunos castellanos que llevaban a vender unos hombres de Borja que habían cautivado en la guerra, los cuales les fueron arrebatados por varios hombres navarros, que consiguieron liberarlos. Y cuando los castellanos denunciaron ante la justicia de Tudela esta acción, considerada como robo, los vecinos de Zaragoza que se hallaban presentes les recriminaron por la mala obra que habían pretendido realizar de llevar a vender cristianos como esclavos ${ }^{85}$.

Los judíos cautivados en acciones de guerra, por el contrario, nos consta que sí eran en ocasiones vendidos como esclavos sin que lo impidiese la interposición de escrúpulos de conciencia que considerasen inmoral tal acto. Y como prueba sirva recordar la azarosa trayectoria de Abraham Alfaqui, hijo de Salamon Alfaqui, quien fue cautivado por los castellanos cuando éstos ocuparon Tarazona, y más adelante fue vendido en Sevilla a un mercader que se lo llevó consigo a Lisboa, donde, en circunstancias no conocidas en detalle, debió de recobrar la libertad. Consiguió, así, regresar al cabo de los años a su ciudad natal, donde tropezó con muchas dificultades para recuperar sus propiedades, que le habían sido ocupadas durante su

${ }^{85}$ ACA, C, reg. 1150-225, Magallón, 13-V-1357. 
prolongada ausencia ${ }^{86}$. Pero, en honor a la verdad, hay que hacer constar que los judíos no sólo estuvieron expuestos al peligro de ser apresados y vendidos como esclavos cuando residían en lugares de frontera en tiempos de guerra, sino también en otros contextos muy diferentes. Así nos lo pone de manifiesto, por ejemplo, una denuncia presentada en 1347 por Benvenist Avincaceç, judío vecino de Valencia, quien hizo saber a las autoridades aragonesas que un leño en el que él transportaba mercancías desde Valencia hasta Mallorca fue atacado por una nave castellana cuando se encontraba cerca del puerto de Santa Eulalia, en los mares de Ibiza. En esta operación, los atacantes no se limitaron a apoderarse de las mercancías que había en el leño, sino que también apresaron a los judíos que viajaban en él y se los llevaron a Sevilla, donde los quisieron vender como esclavos. Finalmente, sin embargo, no lo hicieron, pues intervinieron para impedirlo varios parientes de los referidos judíos, que residían en la capital andaluza ${ }^{87}$.

Por otro lado, muchos de los judíos apresados en acciones de guerra no llegaron a ser vendidos como esclavos, pero en contrapartida sufrieron penosos desplazamientos fuera de sus lugares y reino de origen, que con frecuencia se les impusieron con la intención de exigir rescates por ellos a sus familiares. Como consecuencia, debieron sobrevivir en precarias condiciones fuera de sus hogares durante prolongados períodos de tiempo, como les ocurrió a varios judíos y mudéjares de la villa aragonesa de Borja, que durante los años de la ocupación castellana fueron tomados como rehenes por el maestre de Calatrava, Diego García de Padilla, quien se los llevó consigo a Castilla tras la evacuación de la ciudad de Tarazona por las tropas castellanas. Todavía a comienzos del año 1366, este grupo de judíos

\footnotetext{
${ }^{86}$ ACA, C, reg. 764-90, Barcelona, 16-VIII-1372. A su regreso a Tarazona denunció a Abraham Arruet, que había sido su tutor, y en su ausencia había vendido gran parte de sus bienes, alegando que le había hecho donación de ellos.

${ }^{87}$ ACA, C, reg. 644-117v Valencia, 12-IV-1347. Carta de Pedro IV al rey de Castilla.
} 
y mudéjares seguía en poder del referido noble castellano, que los mantenía presos en su fortaleza de Zorita, en la actual provincia de Guadalajara ${ }^{88}$.

Además, en el ambiente revuelto de la guerra, los judíos no sólo sufrieron con mayor intensidad los efectos de la violencia desplegada por los enemigos, sino que también estuvieron más expuestos a resultar víctimas de los abusos cometidos por sus propios conciudadanos. Así nos lo demuestra el caso de Çadiano Alborge, judío de Tarazona, quien, cuando las tropas de ocupación castellanas evacuaron esta ciudad, se vio obligado a marchar tras ellas para intentar recuperar a un hijo suyo que se habían llevado cautivo. Entonces, aprovechando su ausencia de la ciudad, muchos convecinos suyos, no sabemos si judíos o cristianos, o miembros de ambas comunidades, entraron por la fuerza en su casa y le robaron todos los bienes que en ella tenía ${ }^{89}$.

Los registros de Cancillería del Archivo de la Corona de Aragón nos proporcionan otras muchas noticias sobre las penalidades sufridas por miembros de las comunidades judías hispanas durante los años de las guerras entre Castilla y Aragón, y muy en particular durante la llamada guerra de los dos Pedros. Pero con los ejemplos aportados basta para advertir cuáles fueron algunas de las consecuencias principales que sobre estas comunidades, y más en particular sobre las que estaban ubicadas en comarcas fronterizas, tuvieron las situaciones bélicas.

En cualquier caso, aunque no cabe ninguna duda de que las guerras entre los monarcas castellanos y aragoneses a lo largo del siglo XIV tuvieron efectos muy negativos sobre las condiciones de vida de sus súbditos judíos, no representaron un obstáculo importante para la libre circulación de éstos entre uno y otro reino, sino que por el

\footnotetext{
${ }^{88}$ ACA, C, reg. 728-38, Zaragoza, 5-V-1366. Cartas de Pedro IV al rey Enrique II de Castilla y a Bertrand Du Guesclin.

${ }^{89}$ ACA, C, reg. 728-68, Zaragoza, 30-VI-1366.
} 
Sef 63: 2 (2003) LA MOVILIDAD DE LOS JUDÍOS A AMBOS LADOS DE LA FRONTERA ENTRE... 281

contrario, en parte, contribuyeron incluso a intensificarla. Por lo tanto, recapitulando, podemos concluir que la fragmentación del espacio peninsular en los siglos bajomedievales en diversos reinos, con estructuras y tradiciones políticas bastante diferentes entre sí, aunque sin duda generó importantes obstáculos para el desarrollo económico del territorio, sobre todo por razón de las limitaciones que impuso al comercio y de los efectos destructivos de las rivalidades entre reinos, no tuvo consecuencias importantes sobre la movilidad de las personas, que cambiaron de residencia con bastante facilidad de unos reinos a otros. 


\section{RESUMEN}

A pesar de que los judíos fueron considerados formalmente como un elemento más del patrimonio regio en los reinos hispanos medievales, por lo que no tenían reconocida plena libertad de movimientos, en la práctica se constata que cambiaron de residencia de unos reinos a otros con notable facilidad. Los propios reyes trataron de potenciar estos cambios, mediante la concesión de privilegios a algunos de ellos, cuando deseaban que pasasen a residir a su reino. Para profundizar en el conocimiento de esta realidad, el autor analiza en este artículo los cambios de residencia protagonizados por judíos entre los territorios de las Coronas de Aragón y Castilla, y sus consecuencias. Así mismo, demuestra que la frontera entre estos dos reinos no representó obstáculo para muchos judíos que practicaron el comercio y el préstamo al otro lado de la misma. Por último, en el artículo se analizan algunas de las consecuencias que sobre las condiciones de vida de los judíos tuvieron los conflictos bélicos entre ambas monarquías durante el siglo XIV.

PALABRAS Clave: Castilla, Aragón, judíos, siglo XIV, comercio, finanzas.

\section{SUMMARY}

Although in theory Jews were considered a simple element of the royal patrimony in the medieval Spanish kingdoms, and consequently they did not enjoy complete freedom of movement, in fact they changed their residence and left one kingdom in order to establish themselves in another one with ease. On the other hand, the kings themselves tried to favour these changes of residence through grants of privileges when they wanted to attract them to their kingdom. In order to advance in the study of this phenomenom, the author analyses in this article the changes of residence between the territories of Aragon and Castile undertaken by the Jews and their consequences. It is shown that the frontier between these kingdoms did not represent an obstacle for many Jews that practised trade and moneylending in the territories beyond it. Finally the author draws attention to some of the consequences that the wars between both monarchies during the fourteenth century had over the conditions of life of the Jews.

KEYwords: Castile, Aragon, Jews, fourteenth century, trade, finance. 